\title{
Effects of Intermetallic Microstructure on Degradation of $\mathrm{Mg}-5 \mathrm{Nd}$ Alloy
}

\author{
YAPING ZHANG, YUANDING HUANG, FRANK FEYERABEND, \\ SARKIS GAVRAS, YULING XU, REGINE WILLUMEIT-RÖMER, \\ KARL ULRICH KAINER, and NORBERT HORT
}

The influence of intermetallic microstructure on the degradation of $\mathrm{Mg}-5 \mathrm{Nd}$ alloy with different heat treatments was investigated via immersion testing in DMEM +10 pct FBS under cell culture conditions and subsequent microstructural characterizations. It was found that T4 heat-treated sample had the poorest corrosion resistance due to the lack of finely dispersed precipitates inside grains, continuous lamellar particles along grain boundaries and outer Ca-P layer, and to the formation of a loose corrosion product layer. In contrast, the aged samples exhibited a better corrosion resistance due to their presence and to the formation of a compact corrosion layer. Their degradation behavior largely depended on the intermetallic microstructure. Corrosion was initiated in the matrix around stable globular particles $\mathrm{Mg}_{41} \mathrm{Nd}_{5}$ at grain boundaries. In the sample aged at high temperature $245^{\circ} \mathrm{C}$, the coexistence of lamellar $\mathrm{Mg}_{41} \mathrm{Nd}_{5}$ particles and their nearby Nd-poor regions enhanced the corrosion. The corrosion first started in such regions. It was shown that those finely dispersed precipitates formed during aging had no influence on the corrosion initiation. However, they indeed affected the subsequent corrosion propagation with the immersion proceeding. They supplied barriers for corrosion propagation and hence were beneficial for improving the corrosion resistance. The continuously distributed lamellar $\mathrm{Mg}_{41} \mathrm{Nd}_{5}$ precipitates formed at grain boundaries during aging at $245^{\circ} \mathrm{C}$ supplied an additional effective obstacle to corrosion propagation. This was especially beneficial for hindering the corrosion propagation at the later stage of corrosion.

https://doi.org/10.1007/s11661-020-05926-7

(c) The Author(s) 2020

\section{INTRODUCTION}

Magnesium is chemically very active. It can interact with other alloying elements to form intermetallic phases. Many of the current developed biodegradable magnesium alloys contain intermetallics. ${ }^{[1-7]}$ When these alloys are immersed in corrosive media, the intermetallic compounds can couple with $\alpha-\mathrm{Mg}$ to result in possible galvanic corrosion. ${ }^{[8-10]}$ The corrosion resistance of $\mathrm{Mg}$ alloys is closely related with the distribution of these intermetallic compounds. Previous investigations indicated that such intermetallic phases with a continuous network distribution can work as a barrier to retard corrosion propagation. ${ }^{[11]}$ For

YAPING ZHANG, YUANDING HUANG, FRANK FEYERABEND, SARKIS GAVRAS, REGINE WILLUMEITRøMER, KARL ULRICH KAINER, and NORBERT HORT are with the Institute of Materials Research, Helmholtz-Zentrum Geesthacht, Max-Planck-Strasse 1, 21502 Geesthacht, Germany. Contact e-mail: yaping.zhang@hzg.de YULING XU is with the Shanghai Spaceflight Precision Machinery Institute, 201600 Shanghai, China.

Manuscript submitted November 30, 2019.

Article published online August 3, 2020 example, in the alloy $\mathrm{AZ91}, \mathrm{Mg}_{17} \mathrm{Al}_{12}$ phase exhibits a dual purpose during corrosion in simulated body fluid, namely acting as micro-cathodes to accelerate corrosion and/or simultaneously supplying barriers to inhibit corrosion due to its different distributions. ${ }^{[4,12,13]}$ The discontinuous $\mathrm{Mg}_{17} \mathrm{Al}_{12}$ phase can work as cathodes and deteriorate the corrosion resistance. Contrary to this, the continuous network of $\mathrm{Mg}_{17} \mathrm{Al}_{12}$ phase formed after $\mathrm{T} 6$ treatment can act as barriers to the corrosion attack. ${ }^{[14]}$ Unlike in Mg-Al alloys, in Mg-Zn alloys, the continuous nanosized $\mathrm{Mg}_{x} \mathrm{Zn}_{y}$ phase precipitated during T6 treatment cannot form a tight barrier to inhibit the corrosion propagation. Both the discrete and continuous $\mathrm{Mg}_{x} \mathrm{Zn}_{y}$ phases behave as micro-cathodes to accelerate the corrosion. ${ }^{[15]}$ Similar features were found in ZK40-2Nd ${ }^{[16]}$ The semi-continuous intermetallic phase in ZK40-2Nd leads to the severe corrosion attack. Nevertheless, in ZK60-3.6Nd, the honeycomb intermetallic phase restrains the propagation of corrosion. ${ }^{[17]}$ Thus, whether corrosion of magnesium alloys is retarded or accelerated is highly influenced by the distribution of intermetallic compounds. 
Intermetallics can be formed at high temperatures during casting or by solid-state transformation at relatively low temperatures. ${ }^{[18]}$ Their precipitations are influenced by the solid solubility of alloying elements in the $\mathrm{Mg}$ matrix. Rare-earth (RE) elements are widely used as the major alloying elements in biodegradable magnesium alloys to improve mechanical properties and to enhance corrosion resistance. Among these RE elements, $\mathrm{Nd}$ has a low solid solubility (3.6 wt pet at the eutectic temperature and almost zero at the room temperature) in $\mathrm{Mg} .{ }^{[19]}$ It was reported to be a suitable element for medical applications. ${ }^{[20]} \mathrm{Nd}$-containing biodegradable magnesium alloys, such as WE43 $3^{[21,22]}$ and WE54, ${ }^{[23,24]}$ are well known for their significant aging response due to its limited solid solubility at lower temperatures. $\mathrm{Mg}-\mathrm{Nd}$ alloys tend to precipitate the metastable phase $\mathrm{Mg}_{3} \mathrm{Nd}$ upon fast cooling or $\mathrm{Mg}_{12} \mathrm{Nd}$ phase at relatively slow cooling during solidification. ${ }^{[25,26]}$ As the stable $\mathrm{Mg}_{41} \mathrm{Nd}_{5}$ phase is usually formed at high temperatures over an extended period of time, ${ }^{[19,27]}$ the metastable $\mathrm{Mg}_{3} \mathrm{Nd}$ or $\mathrm{Mg}_{12} \mathrm{Nd}$ phase is often observed in the microstructures of many developed Mg-Nd alloys. ${ }^{[25,28-33]}$ Regarding the corrosion properties of these $\mathrm{Mg}-\mathrm{Nd}$ second phases, the corrosion potential $\left(V_{\mathrm{SCE}}\right)$ of $\mathrm{Mg}_{3} \mathrm{Nd}$ was measured to be -1.55 $\mathrm{V}$, which is slightly higher than that of $\mathrm{Mg}(-1.65 \mathrm{~V}) .^{[34]}$ Compared with those intermetallics such as $\mathrm{MgZn}_{2}$ ($1.03 \mathrm{~V})$ and $\mathrm{Mg}_{17} \mathrm{Al}_{12}(-1.35 \mathrm{~V}),{ }^{[34]} \mathrm{Mg}_{3} \mathrm{Nd}$ phase is relatively less noble. The potential of $\mathrm{Mg}_{12} \mathrm{Nd}$ phase is also a little more positive than that of pure $\mathrm{Mg} .{ }^{[35]}$ Both the metastable $\mathrm{Mg}_{3} \mathrm{Nd}$ and $\mathrm{Mg}_{12} \mathrm{Nd}$ exhibit a slight negative influence on the corrosion of magnesium alloys caused by micro-galvanic corrosion. A similar less cathodic precipitate IM1 $\left(\mathrm{Ca}_{3} \mathrm{Mg}_{x} \mathrm{Zn}_{15-x}, 4.6 \leq x \leq\right.$ 12) was also reported in $\mathrm{Mg}-\mathrm{Zn}-\mathrm{Ca}$ system. ${ }^{[36-38]}$ In a word, the stability of particles, i.e., whether it is metastable or equilibrium phase, also affects the corrosion behavior of alloys.

Influence of microstructure on corrosion resistance of magnesium alloys, especially the impurity, alloying element, grain size and large second phase has been extensively investigated. In contrast, those investigations on the effects of fine precipitates (amount, size and distribution) and their stability received less attentions. To our knowledge, no reports about the investigations on how the intermetallic type and distribution in $\mathrm{Mg}-\mathrm{Nd}$ alloys affect their corrosion properties exist. In this work, the Mg-5Nd alloy was selected for investigations, which was prepared by hot extrusion. Our previous work indicated that after hot extrusion the stable $\mathrm{Mg}_{41} \mathrm{Nd}_{5}$ phase exists in $\mathrm{Mg}-5 \mathrm{Nd}$ alloy. ${ }^{[39]}$ The reason for choosing such a content of $5 \mathrm{wt}$ pct $\mathrm{Nd}$, which is slightly higher than the limit of solid solubility at $\mathrm{Mg}-\mathrm{Nd}$ eutectic temperature, is to retain a part of undissolved stable $\mathrm{Mg}_{41} \mathrm{Nd}_{5}$ phase after solid solution treatment. In addition, it offers chances to modify both the phase types and distributions of intermetallics using heat treatments. Consequently, the alloys with different phase types and distributions could be prepared. Their in vitro degradation tests were performed in DMEM (Dulbecco's modified Eagles' medium) + 10 pct FBS
(Fetal Bovine Serum) under cell culture conditions. The mechanisms responsible for corrosion were discussed.

\section{EXPERIMENTAL}

\section{A. Materials}

Permanent mold direct chill casting was used to prepare $\mathrm{Mg}-5 \mathrm{Nd}$ alloy. ${ }^{[40]}$ High-purity magnesium (Magnesium Electron, Manchester, UK, 99.94 wt pct) was first melted in a mild steel crucible (1.0044, EU Grade) with atmospheric protection $\left(\mathrm{Ar}+2\right.$ pct $\left.\mathrm{SF}_{6}\right)$. Then pure neodymium (Grirem, Beijing, China, $99.5 \mathrm{wt}$ pct) was added at a melt temperature of $750{ }^{\circ} \mathrm{C}$. After being stirred at $200 \mathrm{rpm}$ for 20 minutes, the melt was then poured into a preheated mild steel mold $\left(500^{\circ} \mathrm{C}\right)$. The diameter of mold is $100 \mathrm{~mm}$ and its length is 220 $\mathrm{mm}$. The filled mold was held at $670{ }^{\circ} \mathrm{C}$ for 30 minutes under a protective atmosphere, then immersed into circulating cooling water at a rate of $10 \mathrm{~mm} / \mathrm{s}$ for solidification. When it was fully immersed, the mold was held in cooling water for 10 seconds. The extrusion billets with a dimension of $93 \mathrm{~mm}$ and a length of 200 $\mathrm{mm}$ were machined from the as-cast ingots. After being homogenized in an electromagnetic induction furnace at $440{ }^{\circ} \mathrm{C}$ for 30 minutes, they were indirectly extruded to cylindrical bars with a diameter of $12 \mathrm{~mm}$ at $450{ }^{\circ} \mathrm{C}$, followed by air-cooling. The extrusion ratio is 1:60 and extrusion rate $0.6 \mathrm{~m} / \mathrm{s}$. The chemical compositions of the as-extruded $\mathrm{Mg}-5 \mathrm{Nd}$ alloy were analyzed by spark discharge optical emission spectroscopy (SD-OES, Spectrolab, M. Spectro Analytical Instrument GmbH, Kleve, Germany) (Table I). The solid solution treatment of extruded samples was carried out at $530{ }^{\circ} \mathrm{C}$ for 24 hours. Based on the characteristics of the aging response for $\mathrm{Mg}-\mathrm{Nd}$ alloys, ${ }^{[25,41]}$ the present aging treatments were performed at two different temperatures $200{ }^{\circ} \mathrm{C}$ and 245 ${ }^{\circ} \mathrm{C}$ for 528 hours, respectively. The aim is to obtain the precipitates with apparent difference in their size and distribution.

The samples for microstructural analysis were ground, mechanically polished, and then etched according to the method reported by Kree et al. ${ }^{[42]}$ and Hort et al. ${ }^{[43]}$ The etchant was a mixture of $8 \mathrm{~g}$ picric acid (Sigma-Aldrich Chemie GmbH, Munich, Germany), 5 $\mathrm{mL}$ acetic acid (Avantor Performance Materials B.V., Arnhem, Netherlands), $10 \mathrm{~mL}$ distilled water and 100 $\mathrm{mL}$ ethanol (REHER \& RAMSDEN NACHFLG. GmbH \& Co. KG, Hamburg, Germany). Microstructures were characterized by an optical microscope (LEICA DMLM, Leica Microsystems Wetzlar GmbH, Wetzlar, Germany) equipped with a digital camera and a scanning electron microscope (SEM, Tescan Vega3 SB, Brno, Czech Republic) equipped with an energy dispersive X-ray analyser (EDS). Grain size analysis was performed using line intercept method according to ASTM E 112-13. [44] Transmission electron microscopy (TEM) was conducted using a CM200 (Philips \& Co., Eindhoven, Netherland) operating at $200 \mathrm{kV}$. TEM foils were prepared by electropolishing in a twin jet system using a solution of 1.5 pet $\mathrm{HClO}_{4}$ and 98.5 pet ethanol 
Table I. Actual Chemical Composition of Mg-5Nd (Wt Pet)

\begin{tabular}{lccccc}
\hline Alloy & $\mathrm{Nd}$ & $\mathrm{Fe}$ & $\mathrm{Cu}$ & $\mathrm{Ni}$ & $\mathrm{Mg}$ \\
\hline $\mathrm{Mg}-5 \mathrm{Nd}$ & $>4.20$ & 0.0173 & 0.0027 & 0.0047 & balanced \\
\hline
\end{tabular}

at a temperature of $-50{ }^{\circ} \mathrm{C}$ and a voltage of $50 \mathrm{~V}$. The texture measurement was performed for the as-extruded Mg-5Nd sample using an X-ray diffractometer (PANalytical X'pert PRO MRD, Malvern, UK) with $\mathrm{Cu}-\mathrm{K} \alpha$ radiation.

\section{B. Immersion Test}

Two types of immersion tests were performed in the present investigation, i.e., short time immersion (5 minutes) and long time immersion (1, 7 and 14 days). The discs with a dimension of $10 \times 1.5 \mathrm{~mm}$ (diameter $\times$ height) were machined from the extruded bars for immersion tests. After ultrasonically cleaned by n-Hexane, acetone and 100 pct ethanol in sequence (each for 20 minutes), they were sterilized in 70 pct ethanol and dried in a clean bench (Heraeus BBD 6620, Thermo Fisher Scientific, Schwerte, Germany) under sterile conditions. The selected immersion medium is DMEM + Glutamax (Dulbecco's modified eagle's medium, $(+)$ $4.5 \mathrm{~g} / \mathrm{L}$ D-Glucose, (+) Pyruvate, Life Technologies, Darmstadt, Germany) together with 10 pct FBS (Fetal Bovine Serum, PAA Laboratories, Linz, Austria) in an incubator (Heraeus BBD 6620, Thermo Fisher Scientific, Schwerte, Germany) under cell culture conditions $\left(37{ }^{\circ} \mathrm{C}, 20\right.$ pet $\mathrm{O}_{2}, 5$ pet $\mathrm{CO}_{2}$ and 95 pet relative humidity). The detailed medium compositions can be found in Reference 45.

Before immersion, the initial weight of samples was recorded. At least six samples were tested for each condition. According to the standard ISO 10993-12 (2008), each sample was immersed in the medium at a ratio of $10 \mathrm{~mL} / \mathrm{g}$ (medium/ sample). ${ }^{[46]}$ During long time immersion, the immersion medium was changed every 2 to 3 days to keep the semi-static immersion test. The $\mathrm{pH}$ value (SENTRON ARGUS X pH-meter, Fisher Scientific GMBH, Schwerte, Germany) and osmolality (Osmomat 030, Gonotec, Berlin, Germany) of the immersion medium were measured before each medium change. The medium without samples was served as controls by which their initial values such as $\mathrm{pH}$ and osmolality were obtained. After immersion, the corroded samples were cleaned with distilled water and 100 pct ethanol. Regarding degradation rate analysis, at least four specimens per incubation time were used for statistically analysis. Two samples were kept to analyze their degradation products and chemical compositions of corrosion layers. The degradation products were removed by immersion in the chromic acid $(180 \mathrm{~g} / \mathrm{L}$ in distilled water, VWR international, Darmstadt, Germany) for 20 minutes at room temperature. After the removal of corrosion products, the sample surfaces were cleaned by vigorous shaking in distilled water and 100 pct ethanol. The mean degradation depth (h) of corroded samples in $\mu \mathrm{m}$ was then calculated using the following equation ${ }^{[47,48]}$ :

$$
h=\frac{10000 \times \Delta m}{A \times \rho}=\frac{D R \times t}{8.76}
$$

where $\Delta m$ is the weight loss in grams, $A$ is the surface area of samples immersed in medium in $\mathrm{cm}^{2}, t$ is the immersion time in hours, $\rho$ is the density of samples in $\mathrm{g} /$ $\mathrm{cm}^{3}$ and $D R$ is the degradation rate in $\mathrm{mm} / \mathrm{y}$. The actual density of the as-extruded $\mathrm{Mg}-5 \mathrm{Nd}$ was measured according to Archimedes' principle using 100 pct ethanol as a fluid and a balance (Sartorius LA 230S analytical balance, Sartorius Corporate Administration GmbH, Göttingen, Germany) for weighting.

XRD measurement (D8 ADVANCE, Bruker Corporation, Karlsruhe, Germany, with $\mathrm{Cu} \mathrm{K} \alpha$ X-ray source) was undertaken to identify the phases in $\mathrm{Mg}-5 \mathrm{Nd}$ alloy and the degradation layer. The operating voltage and current were $40 \mathrm{kV}$ and $40 \mathrm{~mA}$, respectively. The scanning step size was $0.01 \mathrm{deg}$ with counting time of 0.5 second per data point. The range of $2 \theta$ values was from 10 to $80 \mathrm{deg}$. The XRD data analysis was performed using BrukerEVA software (Bruker AXS, Version 4.1.1, PDF-2 Release 2015 RDB).

The samples after immersion for 14 days were mounted in resin with the cross-section oriented upwards followed by grinding and fine polishing with $0.25 \mu \mathrm{m}$ diamond suspension (Schmitz-Metallographie $\mathrm{GmbH}$, Aachen, Germany) and fumed silica suspension (CLOEREN TECHNOLOGY GmbH, Wegberg, Germany). Backscattered electron (BSE) imaging and chemical element mapping of the cross-sections of samples were performed by SEM and EDS at an accelerating voltage of $15 \mathrm{kV}$.

The statistical analysis was performed using the software Origin 2017 (OriginLab Corporation, Northampton, USA). Standard analysis comparing more than two treatments was done by one-way analysis of variance (ANOVA) on ranks with Dunn's multiple comparison post hoc tests.

\section{RESULTS}

\section{A. Microstructure}

The microstructural morphologies of extruded Mg-5Nd alloy after T4 treatment, aging treatments at $200{ }^{\circ} \mathrm{C}$ and $245{ }^{\circ} \mathrm{C}$ (labeled as T4, A200 and A245, respectively) were observed in the transversal direction (Figure 1(a) through (d)). After T4 treatment, the undissolved intermetallic phases are distributed mainly at grain boundaries. During hot extrusion, the dynamic recrystallization occurred. The new grains nucleated at these undissolved particles. As shown in Figure 1(a), the grains are still small with a size of about $16.3 \mu \mathrm{m}$ (Table II) even after solid solution annealing at a higher temperature of $530{ }^{\circ} \mathrm{C}$. This demonstrates that the grains were thermally stable during annealing (Table II). Their grain boundaries were effectively pinned by the small particles. The average grain sizes of extruded $\mathrm{Mg}-5 \mathrm{Nd}$ after different heat treatments are 

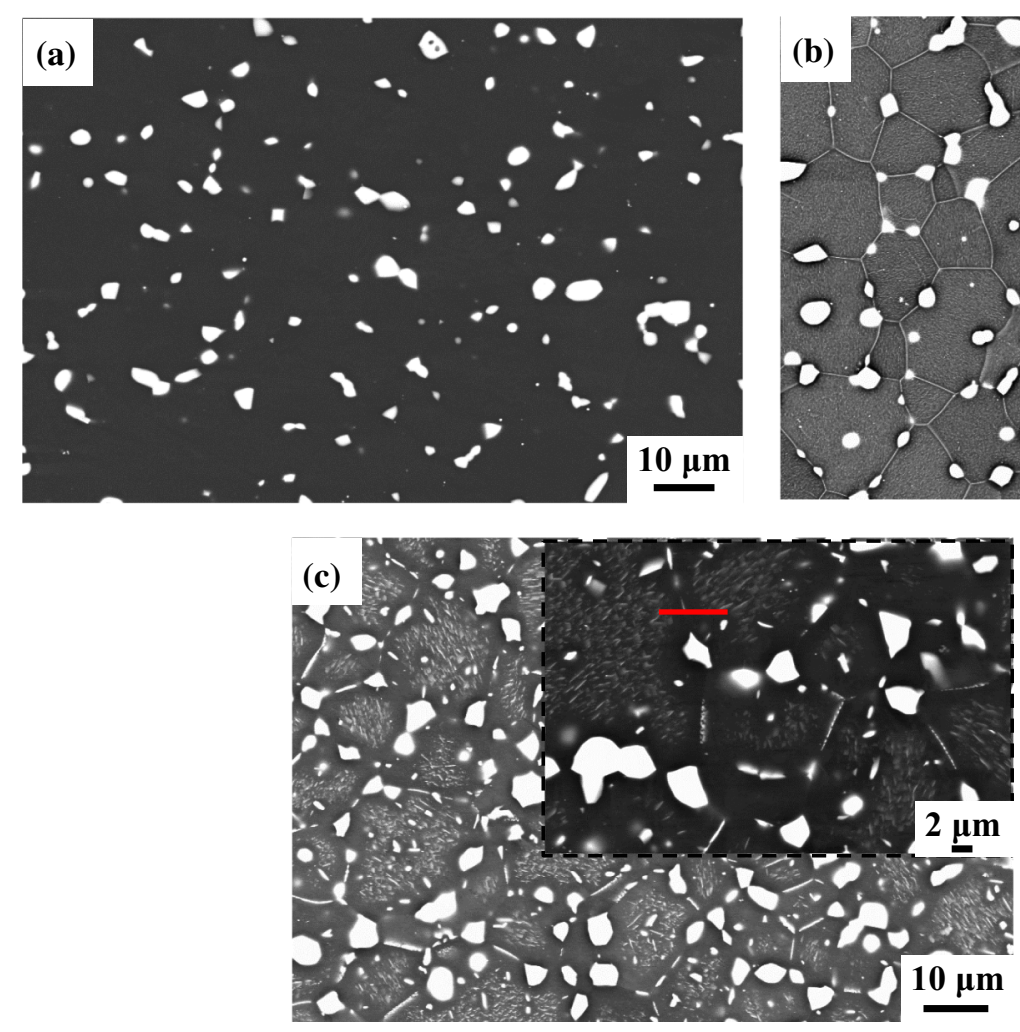

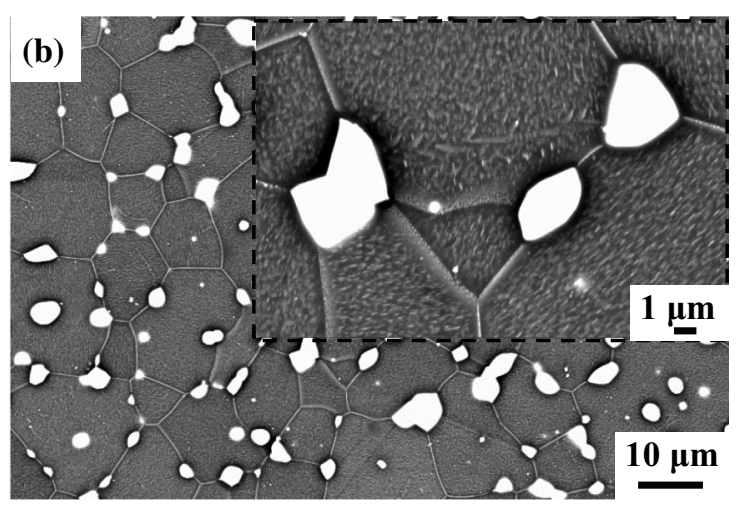

(d)

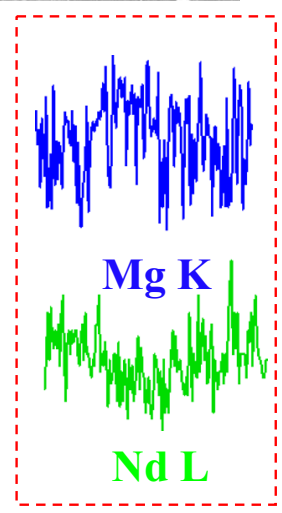

Fig. 1-BSE images of extruded $\mathrm{Mg}-5 \mathrm{Nd}$ alloy after $(a) \mathrm{T} 4$ treatment, $(b)$ T6 treatment at $200{ }^{\circ} \mathrm{C},(c)$ T6 treatment at $245{ }^{\circ} \mathrm{C}$, and $(d)$ the corresponding line scan result (shown as a red bar) of EDS across grain boundary in (c) (Color figure online).

Table II. Grain Sizes on the Transversal Section for Mg-5Nd Alloy with Different Heat Treatments

\begin{tabular}{lc}
\hline Samples & Size $(\mu \mathrm{m})$ \\
\hline T4 & $16.3 \pm 0.4$ \\
A200 & $16.5 \pm 1.0$ \\
A245 & $18.3 \pm 2.1$ \\
\hline
\end{tabular}

approximately $16-18 \mu \mathrm{m}$ (Table II). In the sample aged at $200{ }^{\circ} \mathrm{C}$ (Figure 1(b), besides these undissolved particles at grain boundaries, new fine intermetallic precipitates were formed at grain boundaries and distributed inside the matrix uniformly. With increasing the aging temperature to $245^{\circ} \mathrm{C}$, both precipitates that are located at grain boundaries and inside the grains grew and coarsened. Due to the rapid growth of precipitates at grain boundaries, the Nd-free bands were produced near the grain boundaries (Figure 1(d)). Their presence was further proved with the assistance of line scanning of EDS. In the regions close to the boundaries, the content of $\mathrm{Nd}$ is apparently lower than that far from the boundaries. When comparing these microstructures after different heat treatments, it can be concluded that during aging the formation of precipitates preferentially started at grain boundaries where the free energy is high. The precipitates at the grain boundaries are much bigger than that inside the grains. In addition, in contrast to the A200 sample, the precipitates formed at the boundaries

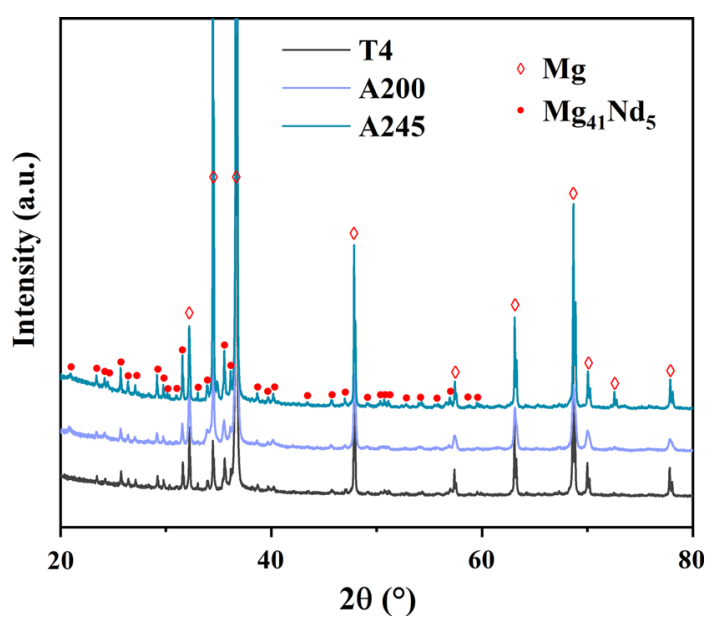

Fig. 2-X-ray diffraction patterns of the extruded $\mathrm{Mg}-5 \mathrm{Nd}$ alloy after different heat treatments.

in the A245 sample easily grew at such a high aging temperature $245{ }^{\circ} \mathrm{C}$. They transformed to a lamellar morphology that were also connected with those large $\mathrm{Mg}_{41} \mathrm{Nd}_{5}$ particles at grain boundaries.

Analysis of X-ray diffraction patterns (Figure 2) revealed that the extruded $\mathrm{Mg}-5 \mathrm{Nd}$ alloy with different heat treatments mainly contained two different phases, i.e., $\alpha-\mathrm{Mg}$ and $\beta-\mathrm{Mg}_{41} \mathrm{Nd}_{5}$. This result is in agreement with that shown in the $\mathrm{Mg}-\mathrm{Nd}$ phase diagram. $\mathrm{Mg}_{41} \mathrm{Nd}_{5}$ is a eutectic phase. It is relatively thermodynamically stable and difficult to dissolve during T4 treatment. 
Thus, in the T4, A200 and A245 samples, this phase was still detected by XRD. When comparing the T4 and A245 samples, it can be found that the peak intensity of $\mathrm{Mg}_{41} \mathrm{Nd}_{5}$ phase in the A245 sample is higher than that in the T4 sample. This demonstrates that during aging at a relatively higher temperature of $245^{\circ} \mathrm{C}$ the additional $\mathrm{Mg}_{41} \mathrm{Nd}_{5}$ was formed. As shown in Figure 1(b), many nanometer-scaled precipitates exist inside the grains of samples aged at the lower temperature $200{ }^{\circ} \mathrm{C}$. XRD seems not to detect these fine precipitates because the intensity of additional peaks for the second phases in the sample aged at $200{ }^{\circ} \mathrm{C}$ is almost the same as that with $\mathrm{T} 4$ treatment. In order to further analyze these fine precipitates formed during aging treatment at $200{ }^{\circ} \mathrm{C}$, the TEM observations were carried out (Figure 3). As shown in Figure 3(a), the plate-shaped and nanoscale precipitates were formed and distributed inside the matrix. The corresponding diffraction pattern (the set of weak diffraction spots) of such precipitates was taken along the zone axis $[11 \overline{11}]_{\mathrm{Mg}}$ (Figure $3(\mathrm{~b})$ ). They were identified as the $\mathrm{Mg}_{12} \mathrm{Nd}$ phase having a body-centered tetragonal structure. This phase is a metastable phase. In summary, in the T4-treated sample, only the equilibrium phase $\mathrm{Mg}_{41} \mathrm{Nd}_{5}$ located at grain boundaries. Aging at the lower temperature $200{ }^{\circ} \mathrm{C}$, in addition to these $\mathrm{Mg}_{41} \mathrm{Nd}_{5}$ particles the metastable phase $\mathrm{Mg}_{12} \mathrm{Nd}$ precipitated both at grain boundaries and inside the grains. With increasing the aging temperature to $245^{\circ} \mathrm{C}$, the amount of $\mathrm{Mg}_{41} \mathrm{Nd}_{5}$ precipitates formed during aging increases, which in turn, reduces the amount of $\mathrm{Mg}_{12} \mathrm{Nd}$ precipitates. This is to say, the sample aged at $245^{\circ} \mathrm{C}$ has the large $\mathrm{Mg}_{41} \mathrm{Nd}_{5}$ particles, fine $\mathrm{Mg}_{41} \mathrm{Nd}_{5}$ precipitates and possible $\mathrm{Mg}_{12} \mathrm{Nd}$ precipitates.

\section{B. Degradation Properties}

1. Short time immersion ( 5 minutes)

Figures 4(a) through (f) show the comparable BSE images from the same observed regions in T4, A200 and
A245 samples before and after corrosion only for 5 minutes. The corresponding chemical element mappings were also taken. In Figure 4(a), besides the second phase $\mathrm{Mg}_{41} \mathrm{Nd}_{5}$, at the right-bottom corner a particle containing impurity $\mathrm{Fe}$ and $\mathrm{Nd}$ was detected. As shown in Table I, this alloy contained $0.0173 \mathrm{wt}$ pet Fe. The detailed compositions of impurity particle are given in Table III. When T4 sample was immersed for 5 minutes, the localized corrosion started in the matrix nearby the isolated particles $\mathrm{Mg}_{41} \mathrm{Nd}_{5}$ and impurities (Figures 4(a) and (b)). In this sample, very few corrosion product spots were observed. Similar corrosion behavior happened in the A200 sample (Figures 4(c) and (d)). The localized corrosion still attacked these regions near such particles $\mathrm{Mg}_{41} \mathrm{Nd}_{5}$. As observed in $\mathrm{T} 4$ sample, at the corrosion spots the impurities $\mathrm{Fe}$ and $\mathrm{Si}$ was also identified. The area of corrosion product spots around them is also the same as that in T4 sample. In this sample, as aforementioned, the precipitation occurred and nanoscale precipitates were formed during aging. However, around such fine precipitates no corrosion product spots were detected. This phenomenon was also observed in the A245 sample aged at the high temperature $245^{\circ} \mathrm{C}$ in which even the precipitates grew slightly. Inside the grains no corrosion occurred where the nanoscale precipitates were homogeneously distributed. As shown in Figure 4(f), in this sample the lamellar structure at grain boundaries appears to accelerate the corrosion. The corrosion product spots are much bigger at grain boundaries in the A245 sample than in the T4 and A200 samples. The area fraction of corrosion spots increases. Unfortunately, in A245 sample, the Fe and Si-containing impurities were not shown although they should exist (Figures 4(e) and (f)). It is much more difficult to identify such very limited Fe-containing impurities among the numerous coarsened precipitates in A245 sample. The EDS mappings of these three corroded samples showed that the compositions of corrosion products had no much difference. All these
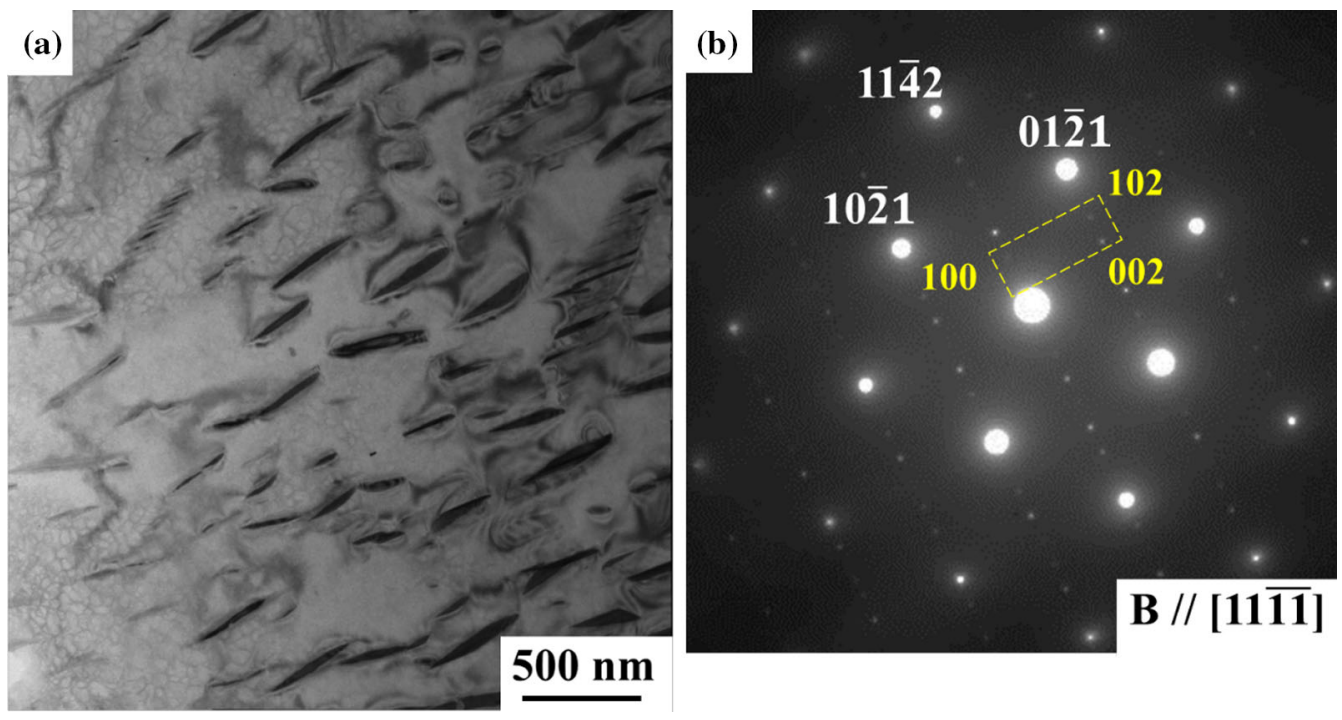

Fig. 3-Transmission electron micrographs recorded from the sample aged at $200{ }^{\circ} \mathrm{C}$ : $(a)$ bright field image and $(b)$ corresponding selected area electron diffraction. 
(a)

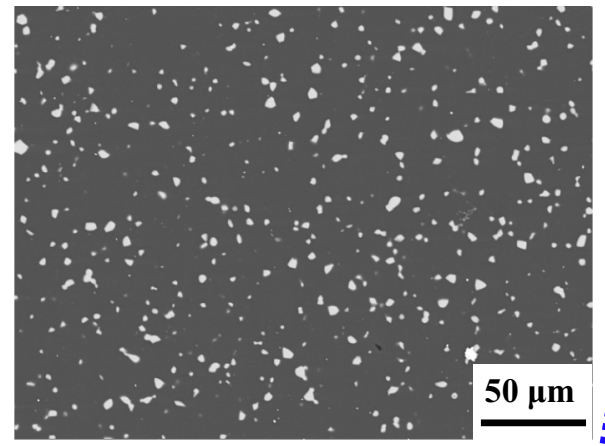

(b)

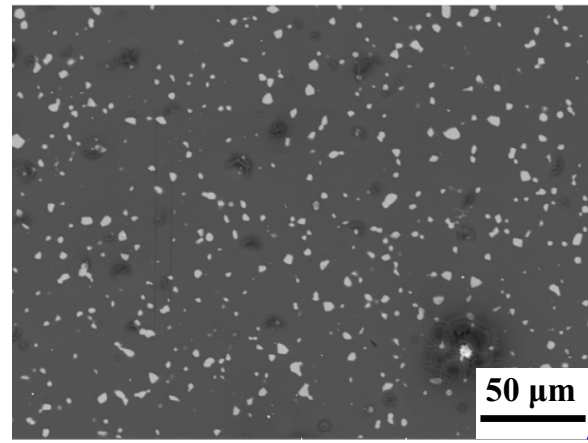

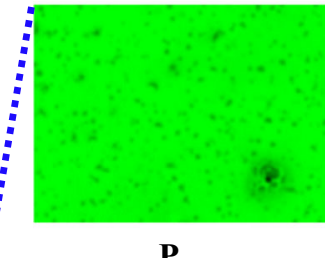

(c)

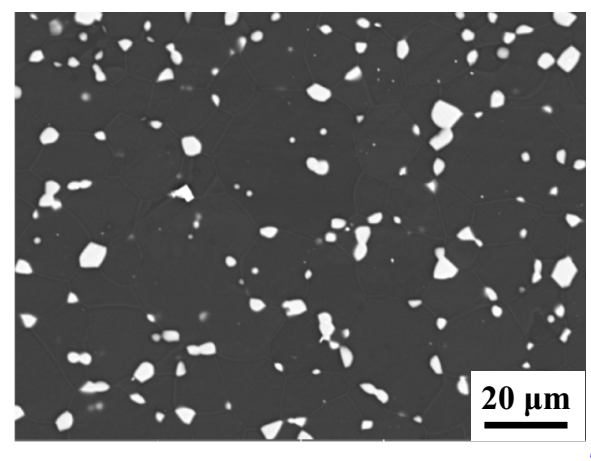

(d)

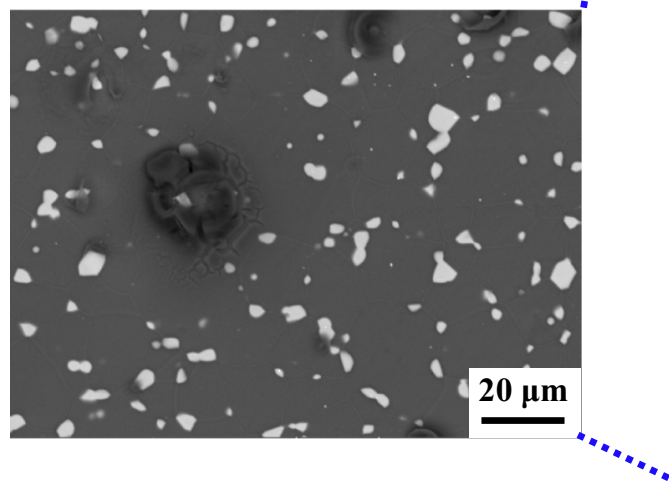

Mg

$\mathbf{P}$

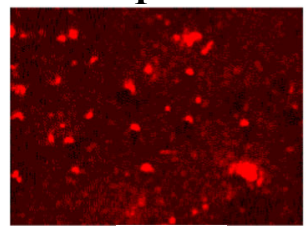

C

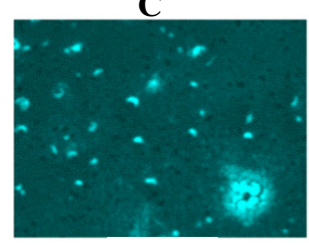

Fe

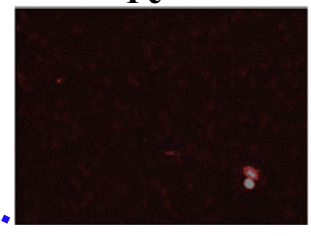

Mg

Nd

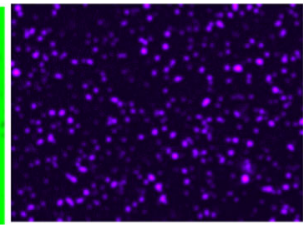

Ca

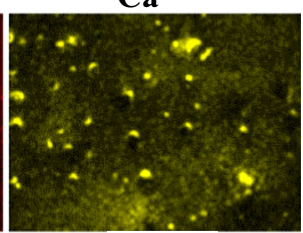

O

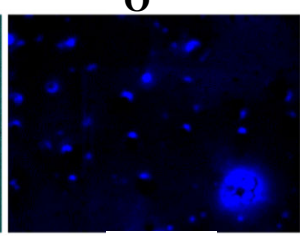

Si

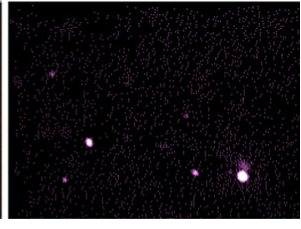

Nd

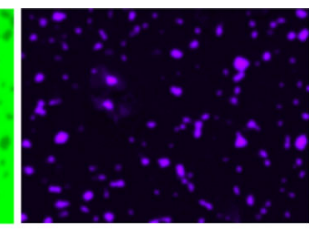

Ca

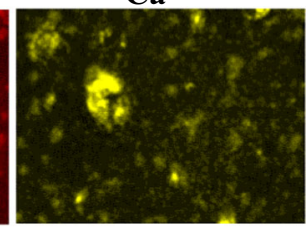

O

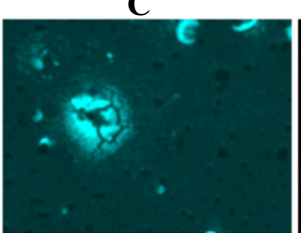

$\mathrm{Fe}$

Si
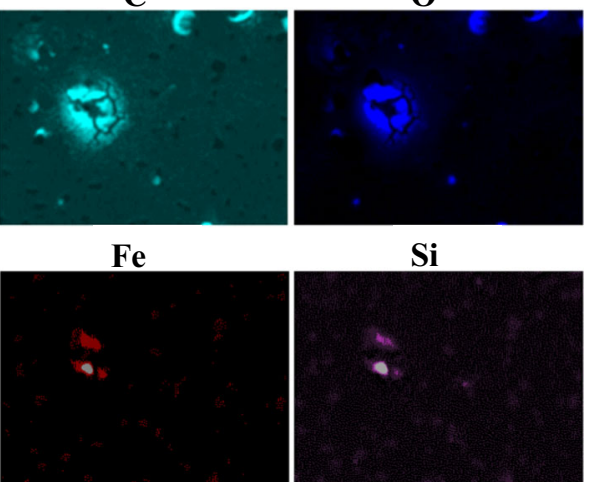

Fig. 4-BSE images: (a) T4 sample before immersion, (b) T4 sample after immersion for 5 min, $(c)$ A200 sample before immersion, (d) A200 sample after immersion for $5 \mathrm{~min}$, (e) A245 sample before immersion, $(f)$ A245 sample after immersion for 5 min, together with corresponding chemical element mappings. 
(e)

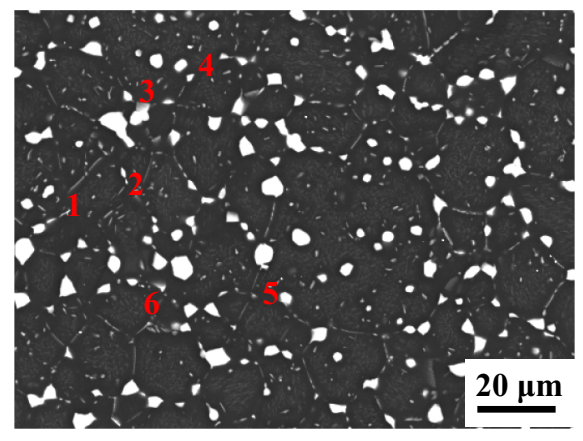

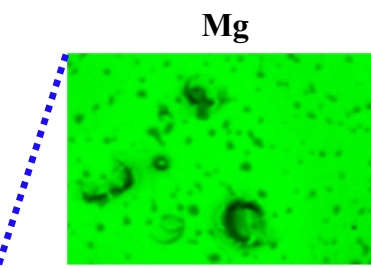

$\mathbf{P}$

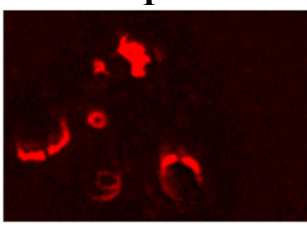

C

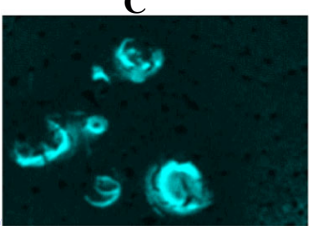

Nd

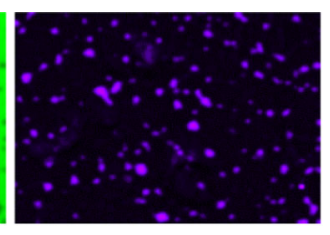

Ca

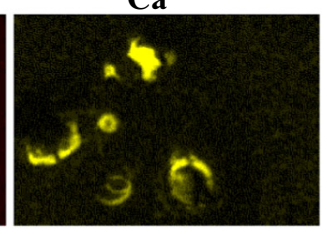

$\mathbf{O}$

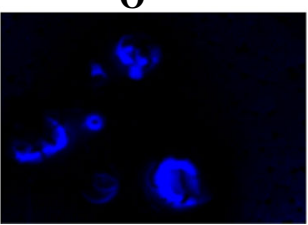

Fig. 4 - continued.

Table III. EDS Results of the Impurity Particle in T4 Sample, Which Locates at the Right-Bottom Corner of Fig. 4(a)

\begin{tabular}{lcccc}
\hline Element & $\mathrm{Mg}$ & $\mathrm{Si}$ & $\mathrm{Fe}$ & $\mathrm{Nd}$ \\
\hline Content (Wt Pct) & 33.7 & 15.1 & 23.3 & 27.9 \\
\hline
\end{tabular}

three corrosion products contained the same elements $\mathrm{C}$, $\mathrm{P}, \mathrm{Ca}$ and $\mathrm{O}$.

\section{Long time immersion}

The degradation rate and mean degradation depths derived from immersion tests are given in Figures 5(a) and (b). Among these three samples, the T4 sample suffered from the severest corrosion. For example, after immersion for 1 day, its degradation rate is $4.4 \pm 0.6$ $\mathrm{mm} / \mathrm{y}$ (Figure 5(a)), but the degradation rates of other two samples are comparably low with a value of less than $2 \mathrm{~mm} / \mathrm{y}$. With increasing immersion time, the corrosion rates of both $\mathrm{T} 4$ and $\mathrm{A} 245$ samples reduce (Figure 5(a)). However, for the A200 sample, its degradation rate does not monotonously decreases. When the immersion time increases from 7 to 14 days, its rate increases from $0.6 \pm 0.3$ to $1.2 \pm 0.6 \mathrm{~mm} / \mathrm{y}$. Interestingly, if comparing the evolution of degradation rates for these two aged samples, it can be found that at the beginning of immersion (1 day) their degradation rates are comparable. When the immersion time increases from 1 day to 7 days, the reduction in the degradation rate is much larger for the A200 sample than that for the A245 sample.

The changes in $\mathrm{pH}$ and osmolality values were monitored at each refreshment of the immersion medium after all the samples were immersed for a specified time (Figures 5(c) and (d)). The results indicated, that after immersion, all the values of $\mathrm{pH}$ and osmolality increased compared to that of controls. The increases in $\mathrm{pH}$ and osmolality were generally higher for the T4 sample than that for A200 and A245 samples. As shown by Figure 5, regarding all immersions, their increase in $\mathrm{pH}$ values was below $0.6(\mathrm{pH}<8.1)$ and their increases of osmolality were less than 0.2 , indicating the present corrosion condition and environment were stable. ${ }^{[49-51]}$

A comparison of surface morphologies of T4, A200 and A245 samples after immersion for different durations is shown in Figure 6. The cracks were present on the surface due to dehydration when the samples were taken out of immersion medium. In the T4 sample, a dense and uniform corrosion surface was observed after immersion for 1 day. The well-formed spherical corrosion products cover its surface after immersion for 7 days. With further immersion for 14 days, in some regions the crystal columnar-like corrosion products grew out above these spherical corrosion products. As observed in the T4 sample, after immersion for 1 day, similar dense and uniform corrosion layers were also observed on the surface of A200 and A245 samples. Inside all the corrosion layers, the globular intermetallic particles $\mathrm{Mg}_{41} \mathrm{Nd}_{5}$ were found. During corrosion, the matrix around them was corroded out and then they 


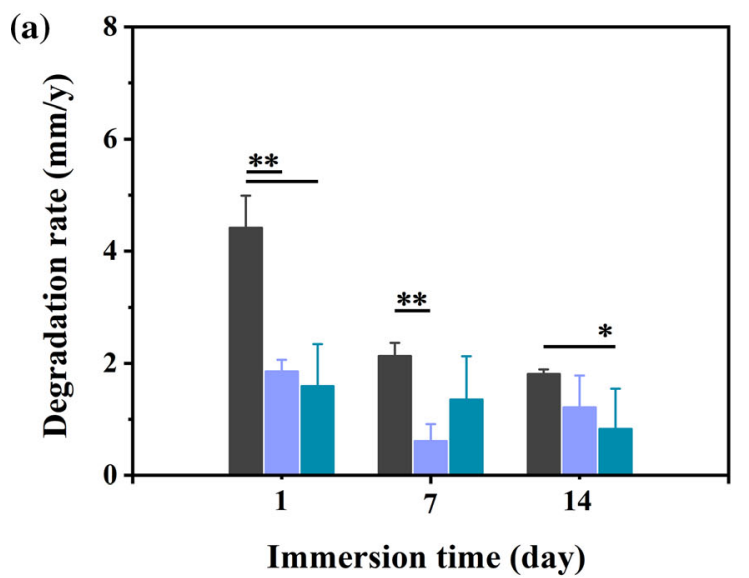

(b)
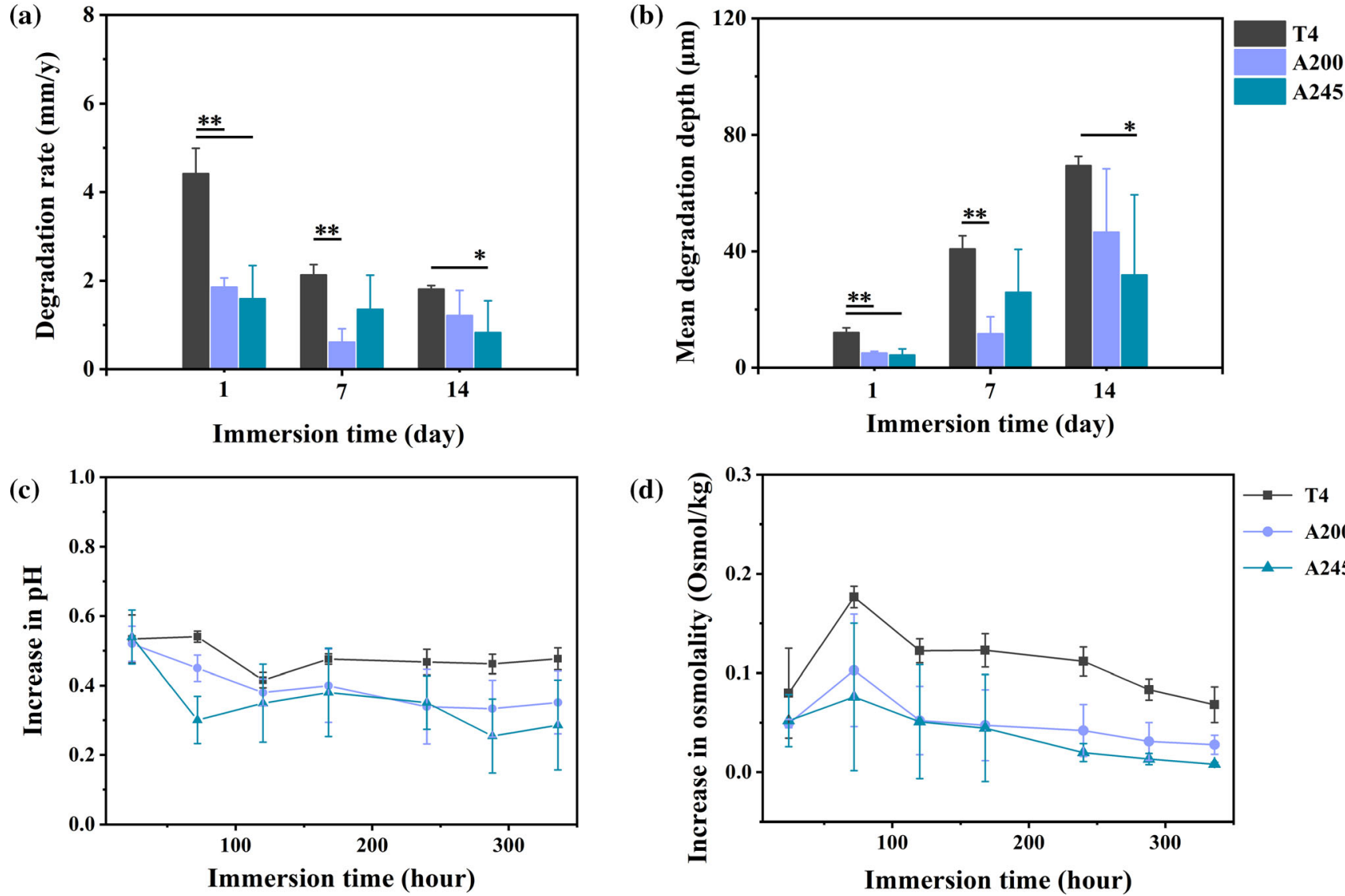

(d)

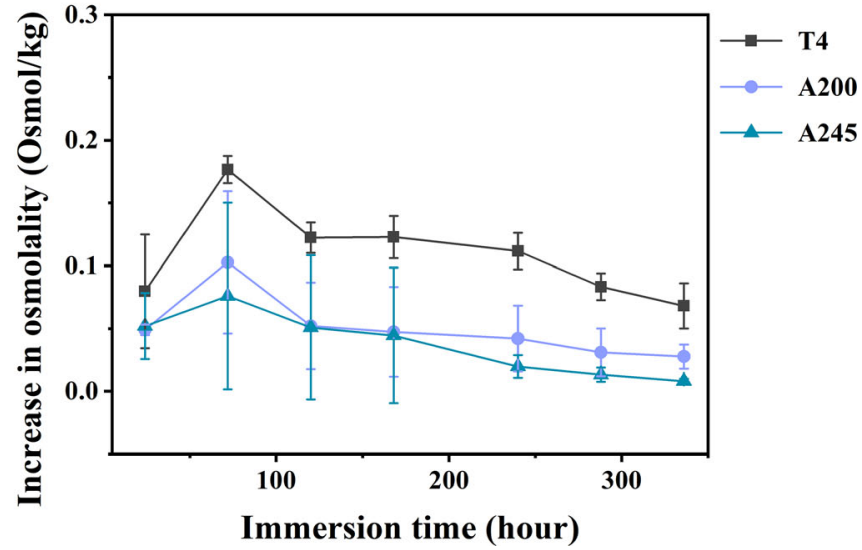

Fig. 5- (a) Degradation rate, $(b)$ mean degradation depth, $(c)$ increase in pH value and (d) increase in osmolality of T4, A200 and A245 samples after different immersion durations. (Statistical significance levels: ${ }^{*} p<0.05$ and ${ }^{* *} p<0.01$ ).

were kept by the newly formed corrosion products. This result demonstrates that the intermetallic compound $\mathrm{Mg}_{41} \mathrm{Nd}_{5}$ is stable in the present corrosion medium. It was not degradable during immersion. For example, as indicated by Figure 6, the distribution of intermetallic $\mathrm{Mg}_{41} \mathrm{Nd}_{5}$ particles in the $\mathrm{A} 245$ sample is still visible after immersion for 1 day. They were gradually covered by the increased corrosion products with immersion for longer durations such as 14 days.

$\mathrm{X}$-ray diffraction patterns of the degradation products formed on the surface of T4, A200 and A245 samples are shown in Figure 7. Their identifications indicate the presence of intermetallics $\mathrm{Mg}_{41} \mathrm{Nd}_{5}$ in the degradation products. This result further confirms its stability in the present corrosion medium. As for the T4 sample, the dense and uniform products after immersion for 1 day were identified as $\mathrm{Mg}_{5}\left(\mathrm{CO}_{3}\right)_{4}(\mathrm{OH})_{2} \cdot 5 \mathrm{H}_{2} \mathrm{O}$ and $\mathrm{MgCO}_{3} \cdot 2 \mathrm{H}_{2} \mathrm{O}$. The well-formed spherical products, formed after immersion for 7 days, also correspond to carbonate-containing products. This is further confirmed by the EDS result (Point 2 in Figure 7) that exhibits the presence of elements $\mathrm{C}, \mathrm{Ca}$ and $\mathrm{P}$ etc. The crystal columnar-like corrosion products formed after immersion for 14 days were mainly $\mathrm{MgCO}_{3} \cdot 3 \mathrm{H}_{2} \mathrm{O}$. This result was consistent with the EDS result (Point 3 in Figure 7) which shows the presence of element $\mathrm{C}$ but without $\mathrm{P}$ and $\mathrm{Ca}$. A comparison of the XRD patterns of the corrosion products for A200 and A245 samples with immersion for different durations was made. From this comparison, it can be shown that the diffraction patterns are similar when they were immersed for the same duration, illustrating that the formed corrosion products should be the same. Inside their corrosion layers, two corrosion products can be identified, i.e., $\mathrm{Mg}_{5}\left(\mathrm{CO}_{3}\right)_{4}(\mathrm{OH})_{2} \cdot 5 \mathrm{H}_{2} \mathrm{O}$ and $\mathrm{MgCO}_{3} \cdot 2 \mathrm{H}_{2} \mathrm{O}$, which are the same as that identified for the corrosion layer of $\mathrm{T} 4$ sample immersed for 1 day. It should be noted here that EDS point analysis (Point 1 in Figure 7) showed the presence of $\mathrm{Nd}, \mathrm{Ca}$ and $\mathrm{P}$ in the corrosion products. However, the identification of diffraction patterns indicated that no $\mathrm{Nd}, \mathrm{Ca}$ and $\mathrm{P}$ containing products were detected. This inconsistency might be caused due to their amount less than the limit of X-ray detection or due to their presence in amorphous state. Several previous examinations showed that the corrosion layers on the surface of magnesium alloys were in an amorphous state. $^{[50,52]}$

Surface morphologies of T4, A200 and A245 samples after removing degradation products were further investigated (Figure 8). The corroded surface of the T4 sample is relatively even, indicating the occurrence of uniform corrosion. No apparent difference was observed for the surface morphologies of samples immersed over different durations. After the removal of corrosion 
T4
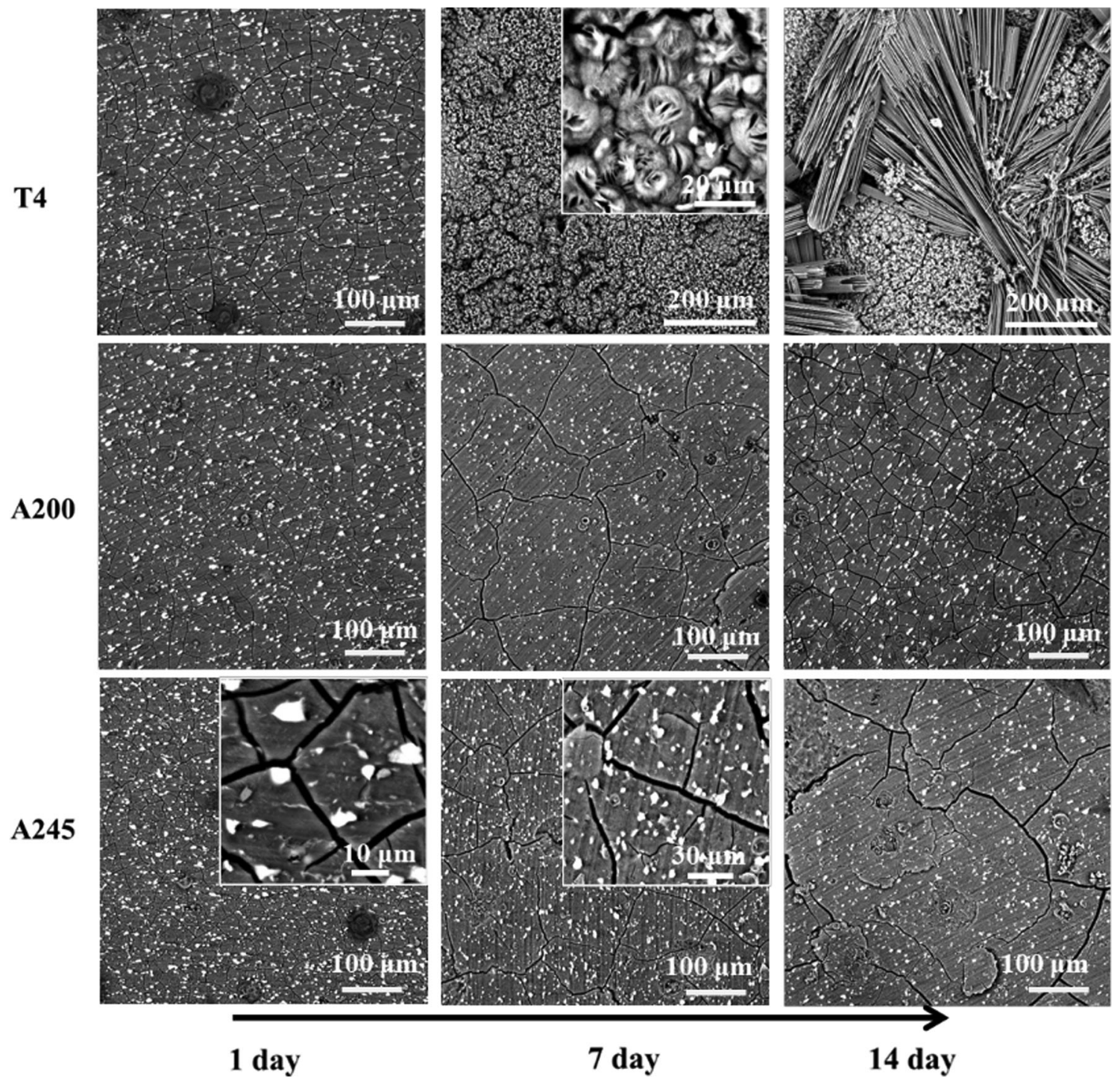

7 day

14 day

Fig. 6-SEM micrographs of the corrosion surfaces for T4, A200 and A245 samples after immersion for 1, 7, and 14 days.

products, the undissolved intermetallic particles and their distribution are clearly visible due to the corrosion of the matrix around them. Some previous small particles diffused into the large particles during the high temperature solution treatment (indicated by blue arrows in Figure 8). This transformation was driven by the reduction of surface free energy. ${ }^{[53]}$ In contrast to the surface of the T4 sample, the surface of A200 sample has a number of corrosion pits (as indicated by red arrows in Figure 8). They appear near the large particles, implying the localized corrosion occurred between the stable $\mathrm{Mg}_{41} \mathrm{Nd}_{5}$ phase and matrix during immersion. With the continuance of immersion, more corrosion pits are observed and the pit diameter increases. The surface becomes rougher and more inhomogeneous. On the surface of the A245 sample aged at higher temperature $245{ }^{\circ} \mathrm{C}$, both the lamellae and undissolved $\mathrm{Mg}_{41} \mathrm{Nd}_{5}$ particles still remained and kept their structures (indicated by the yellow arrows in Figure 8). When the A245 sample was immersed into the medium, the localized corrosion seemed to first start in these regions near the lamellae at grain boundaries. As shown by the yellow arrow (indicated in Figure 8) in the micrograph of A245 sample immersed for 1 day, the 3D morphology of lamellar particle is clearly visible due to the corrosion of its surrounding matrix. With the immersion time increased to 7 days, the corrosion propagated into the matrix. The particles at the grain boundaries stood out from the surface more apparently (yellow arrow in Figure 8). Owing to the corrosion of matrix, the interior region of grains was much lower than its surroundings (shown in yellow dots in Figure 8). With a further immersion duration to 14 days, the surface of the A245 sample became more uneven. The depth of grain interior related to its surrounding lamellar particles increased (see the yellow marks in Figure 8).

Figures 9(a) through (c) show the cross-sectional BSE micrographs of degradation layers on the surface of T4, A200 and A245 samples after immersion for 14 days. Their corresponding chemical element mappings were 


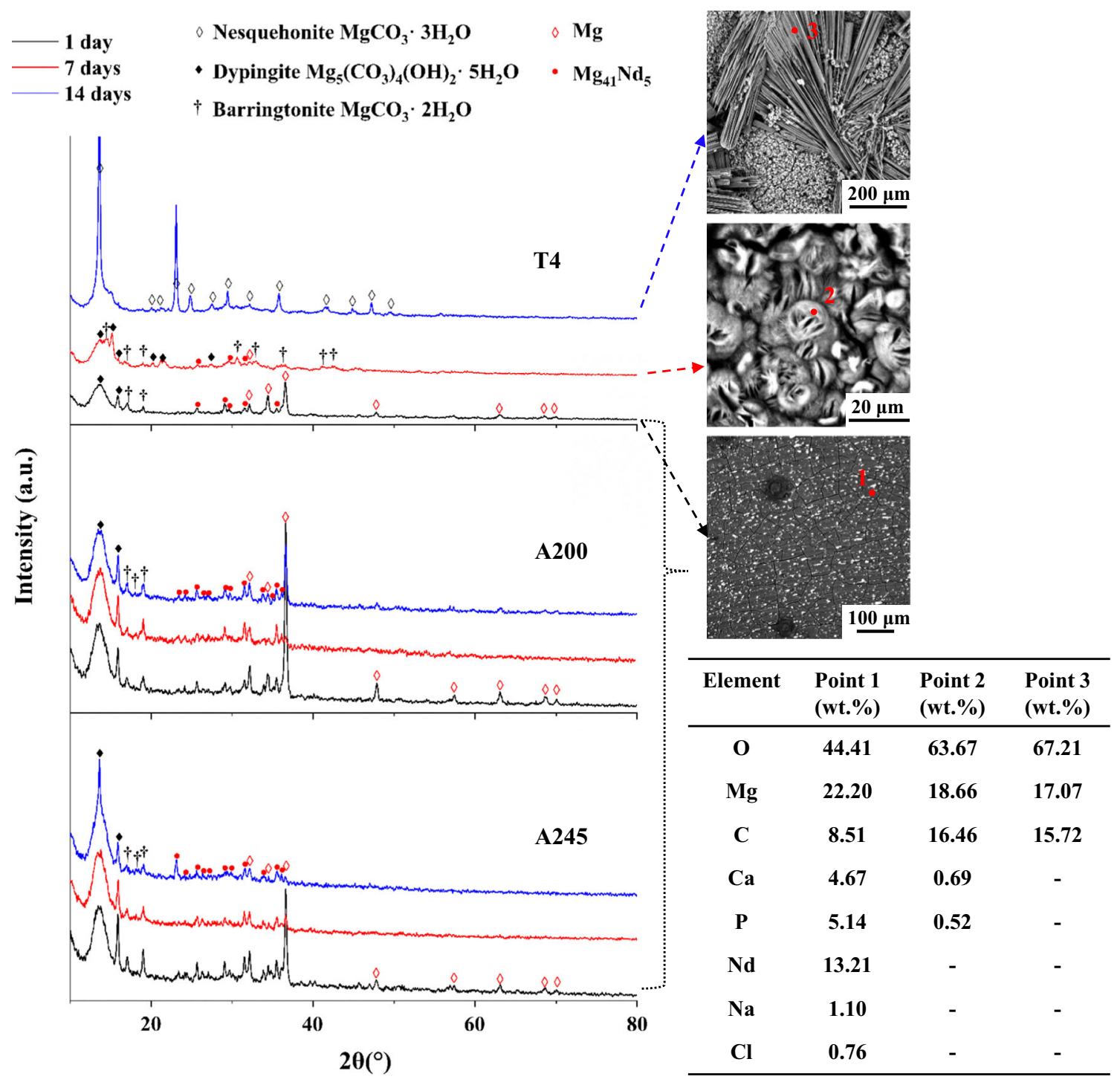

Fig. 7-X-ray diffraction patterns, corresponding morphologies and point EDS results of corrosion products on the surface of T4, A200 and A245 samples after immersion for 1, 7, and 14 days. The locations of point analyses are indicated by the red numbers in the images.

also included. Several interesting results can be obtained from these microstructural characterizations. Firstly, the interface between the corrosion layer and matrix is quite different among these three alloys. It is much smoother in the T4 sample, further supporting that the corrosion of T4 sample proceeded in the way of uniform corrosion. This is in agreement with that obtained by the observations of corrosion surface (Figure 8). With the corrosion duration increasing, the interface became coarser. The serration of interface in A245 sample is quite apparent (blue arrows in Figure 9(c)). Secondly, as shown by the cross-section observations, in the T4 sample a very coarse outer layer was observed. In contrast, on the surfaces of other two samples, this could not be found. Their outer surfaces are quite flat. Thirdly, the EDS mapping indicated that all the corrosion layers contain $\mathrm{Mg}, \mathrm{Nd}, \mathrm{P}, \mathrm{Ca}, \mathrm{C}$ and $\mathrm{O}$ elements. However, their distributions are different in the corrosion layer. In the aged samples A200 and A245, an outer layer with $(\mathrm{Ca}, \mathrm{P})$-enriched was observed (red arrows in Figure 9), but in the T4 sample it did not exist. Finally, the observations of cross-sections clearly demonstrate that the thickness of degradation layers in T4, A200 and A245 samples increased in the order: A245 (Figure 9(c)) < A200 (Figure 9(b)) $<$ T4 (Figure 9(a)). The big intermetallic compound $\mathrm{Mg}_{41} \mathrm{Nd}_{5}$ particles could not degrade and were embedded inside the corrosion layer during immersion. This result concludes that the corrosion of $\mathrm{Mg}-5 \mathrm{Nd}$ alloy propagated inside the matrix.

\section{DISCUSSION}

\section{A. Microstructure}

In Mg-Nd alloys, the decomposition of supersaturated $\alpha-\mathrm{Mg}$ has been extensively investigated..$^{[54-56]}$ The following precipitation sequence was concluded: S.S.S.S. 


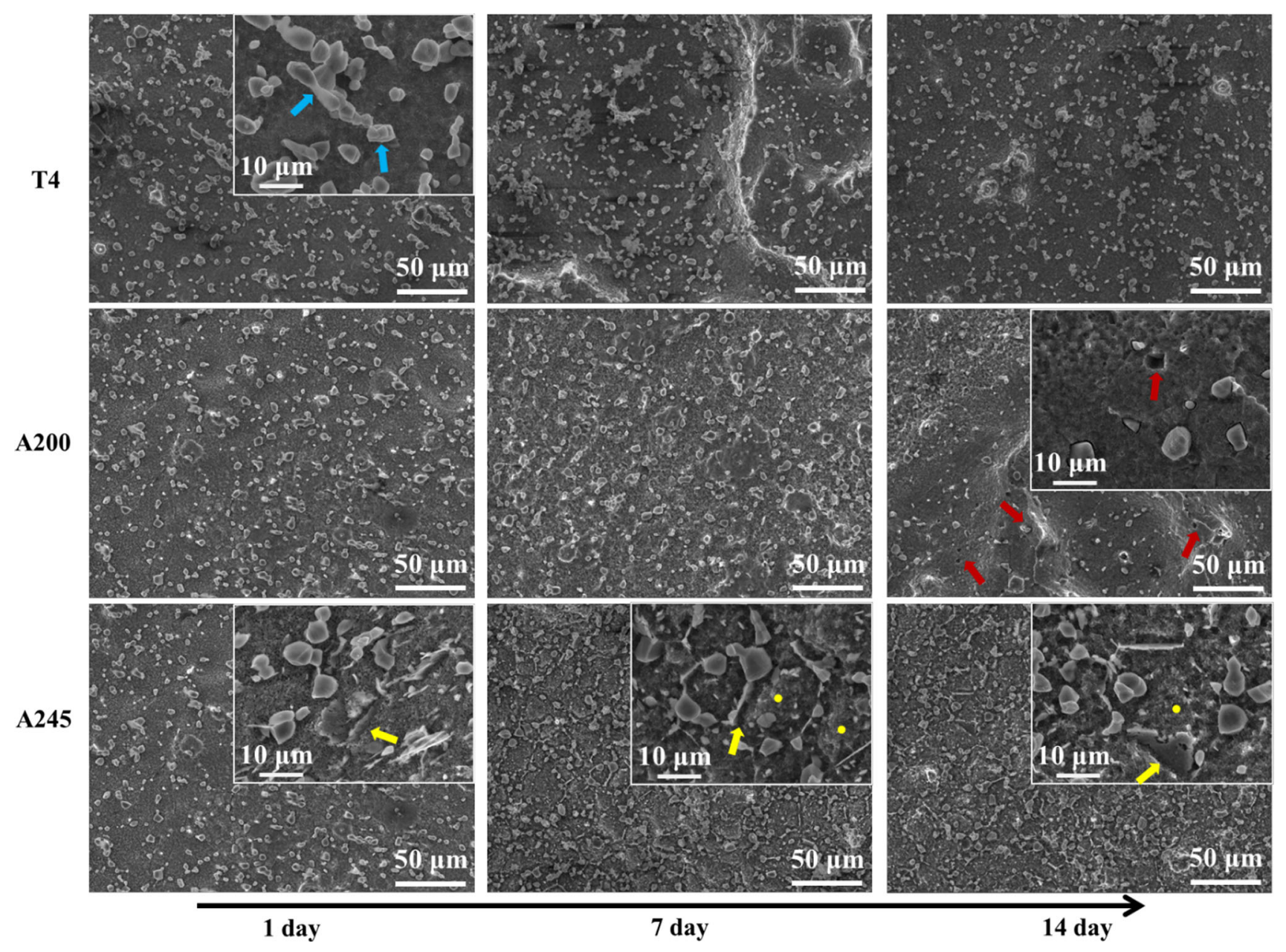

Fig. 8 - Surface morphologies of T4, A200 and A245 samples after removing the degradation products.

$\rightarrow$ ordered G.P. zones $\rightarrow \beta^{\prime \prime}\left(\mathrm{Mg}_{3} \mathrm{Nd}, \mathrm{D} 0_{19}\right) \rightarrow \beta^{\prime}$ $\left(\mathrm{Mg}_{7} \mathrm{Nd}\right.$, cbco $) \rightarrow \beta_{1}\left(\mathrm{Mg}_{3} \mathrm{Nd}\right.$, fcc $) \rightarrow \beta\left(\mathrm{Mg}_{12} \mathrm{Nd}\right.$, bct $)$ $\rightarrow \beta_{\mathrm{e}}\left(\mathrm{Mg}_{41} \mathrm{Nd}_{5}\right.$, bct). It has been shown that $\beta_{1}$ forms as a coherent or semi-coherent metastable phase before the relatively more stable phase $\beta\left(\mathrm{Mg}_{12} \mathrm{Nd}\right)$. The equilibrium intermetallic phase is $\mathrm{Mg}_{41} \mathrm{Nd}_{5}$ in $\mathrm{Mg}-\mathrm{Nd}$ binary system. ${ }^{[19,27,57]}$ However, it was reported that this stable $\mathrm{Mg}_{41} \mathrm{Nd}_{5}$ phase is difficult to precipitate. It was mostly likely observed in those $\mathrm{Mg}-\mathrm{Nd}$ alloys cooled particularly slowly or annealed at high temperatures for a very long time.${ }^{[19]}$ Easton et al.${ }^{[25]}$ reported that after annealing treatment at $500{ }^{\circ} \mathrm{C}$ for 96 hours the metastable second phases $\mathrm{Mg}_{3} \mathrm{Nd}$ and $\mathrm{Mg}_{12} \mathrm{Nd}$ in high pressure die casting $\mathrm{Mg}-8 \mathrm{Nd}$ alloy were transformed to stable $\mathrm{Mg}_{41} \mathrm{Nd}_{5}$ phase. During aging at low temperatures, it took more than 100,000 hours to precipitate out. $^{[41]}$

In the present investigations, the same situation occurs, i.e., the formation of second phases largely depends on the conditions of preparation processes. After T4 treatment, only the equilibrium second phase $\mathrm{Mg}_{41} \mathrm{Nd}_{5}$ was identified. Notably, our previous work ${ }^{[39]}$ demonstrated that in the as-extruded $\mathrm{Mg}-5 \mathrm{Nd}$ alloy the second phase is $\mathrm{Mg}_{41} \mathrm{Nd}_{5}$ rather than $\mathrm{Mg}_{12} \mathrm{Nd}$. Before the present $\mathrm{Mg}-5 \mathrm{Nd}$ alloy was extruded at high temperature $450{ }^{\circ} \mathrm{C}$, a homogenization treatment was performed at $440{ }^{\circ} \mathrm{C}$. These two processes (homogenization annealing and hot extrusion) are beneficial for the transformation of metastable $\mathrm{Mg}_{12} \mathrm{Nd}$ in the as-cast $\mathrm{Mg}-\mathrm{Nd}$ alloy to the stable phase $\mathrm{Mg}_{41} \mathrm{Nd}_{5}$. During hot extrusion, the high deformation at high temperature $450{ }^{\circ} \mathrm{C}$ could enhance such a phase transformation. It was reported that the deformation by friction stir processing induced the transformation of I-phase to W-phase in Mg-6Zn-1Y-0.5Zr alloy. ${ }^{[58]}$ The subsequent $\mathrm{T} 4$ treatment at much higher temperature $530{ }^{\circ} \mathrm{C}$ in the present investigation also stabilized the existence of $\mathrm{Mg}_{41} \mathrm{Nd}_{5}$ and further completed the transformation of metastable phase to stable phase.

In the $\mathrm{T} 4$ sample, the alloying element $\mathrm{Nd}$ was supersaturated at low temperatures. The present aging treatment resulted in its precipitation in the form of fine $\mathrm{Mg}_{12} \mathrm{Nd}$ particles which were homogenously distributed inside grains. Their presence was confirmed by TEM observations (Figure 3). Owing to the low aging temperature of $200{ }^{\circ} \mathrm{C}$, the precipitation kinetics is not high enough to precipitate the stable phase $\mathrm{Mg}_{41} \mathrm{Nd}_{5}$. When the aging temperature was increased to $245{ }^{\circ} \mathrm{C}$, the driving force caused by the thermal activation increased. The $\mathrm{Mg}_{12} \mathrm{Nd}$ phase grew inside grains, and even some blocky particles can be observed (Figure 1(c)). It is reasonable to conclude that a part of such 
(a)

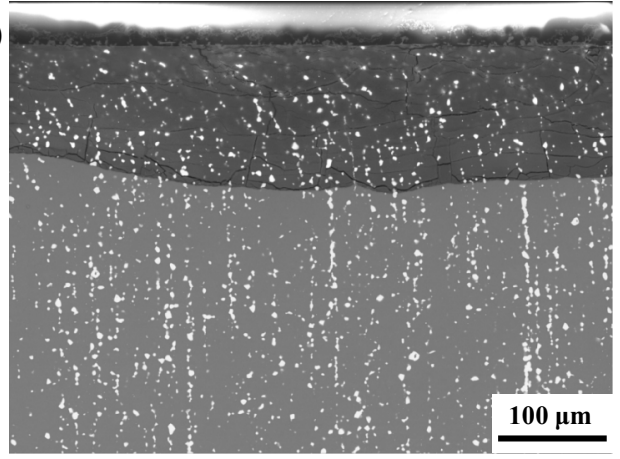

(b)

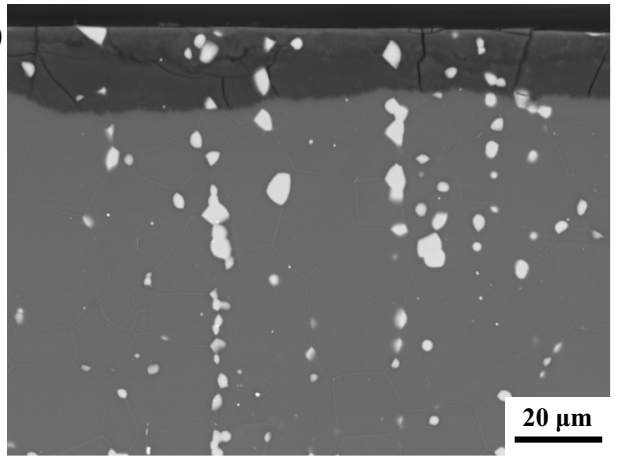

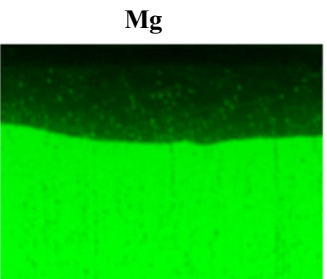

$\mathbf{P}$

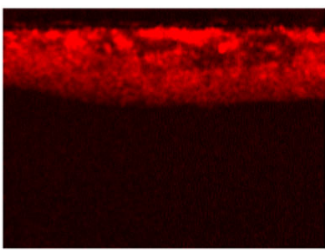

C

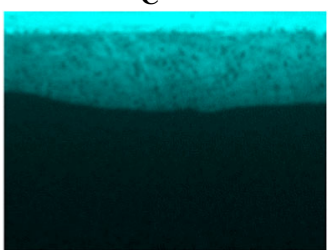

Mg

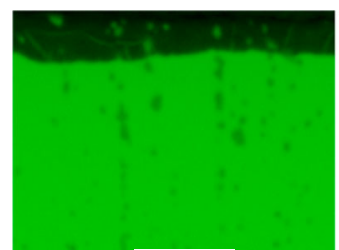

$\mathbf{P}$

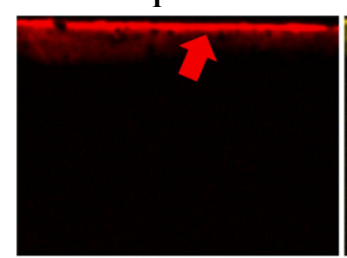

C

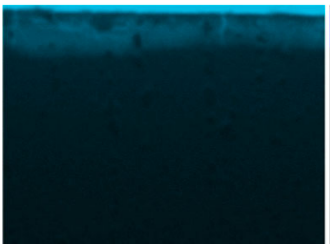

Nd

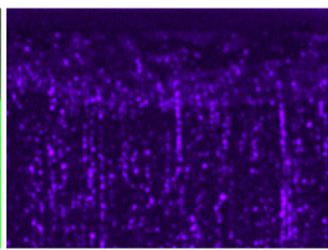

Ca

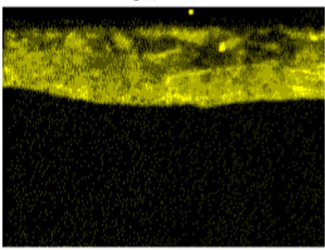

o

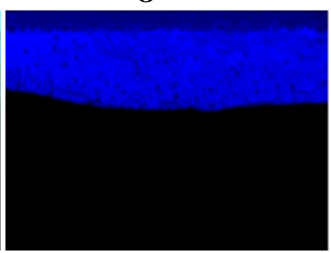

Nd

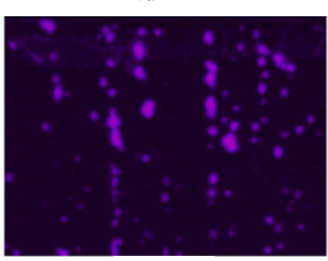

Ca

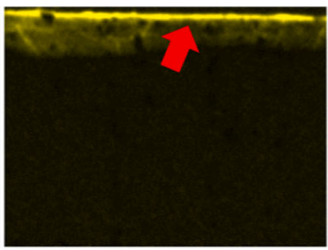

o

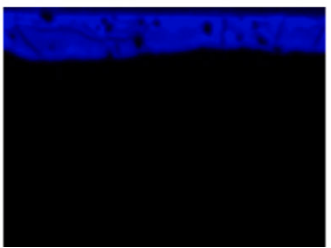

Fig. 9-Cross-sectional BSE micrographs and corresponding chemical element mappings of (a) T4, (b) A200 and (c) A245 samples after immersion for 14 days.

metastable $\mathrm{Mg}_{12} \mathrm{Nd}$ phase in the A200 sample transformed to the stable $\mathrm{Mg}_{41} \mathrm{Nd}_{5}$ phase in the A245 sample. Such a phase transformation therefore led to the increment in the intensity of $\mathrm{Mg}_{41} \mathrm{Nd}_{5}$ diffraction peaks in the A245 sample (Figure 2). Based on the microstructural observations (Figures 1 and 8), during aging at the higher temperature $245{ }^{\circ} \mathrm{C}$, it was determined that the growth and phase transformation of precipitates preferentially started at grain boundaries. Owing to the solute $\mathrm{Nd}$ having a high diffusivity there ${ }^{[59]}$ the lamellar phase $\mathrm{Mg}_{41} \mathrm{Nd}_{5}$ was firstly formed at grain boundaries.
Under such a condition, due to the rapid consumption of $\mathrm{Nd}$ by the formation of lamellar $\mathrm{Mg}_{41} \mathrm{Nd}_{5}$ phase and its quick growth, the Nd-poor regions near it were then formed (Figures 1(c) and (d)).

\section{B. Degradation Properties}

In the $\mathrm{Mg}-5 \mathrm{Nd}$ alloy, a relatively high amount of impurity $\mathrm{Fe}(0.0173 \mathrm{wt}$ pct) was measured. Previous investigations demonstrated that its presence is harmful for corrosion resistance of magnesium alloys. ${ }^{[60,61]}$ Its 
(c)

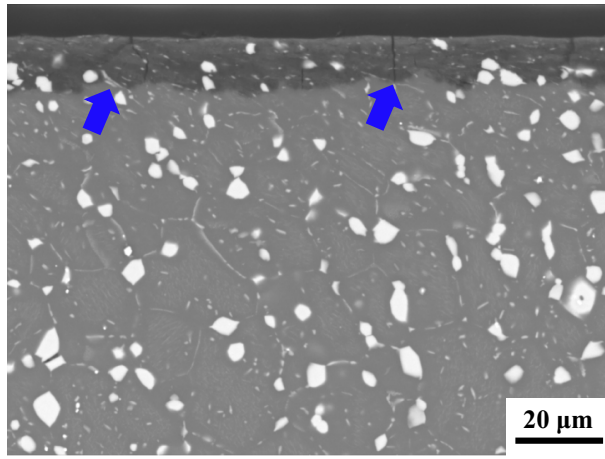

Mg

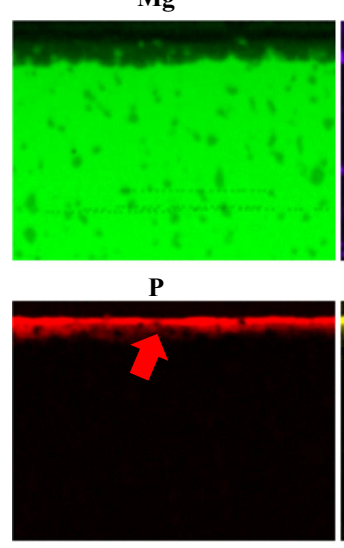

C

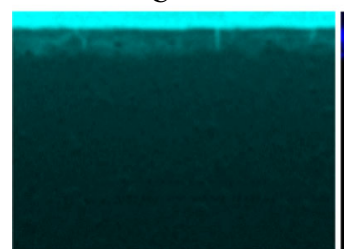

Nd

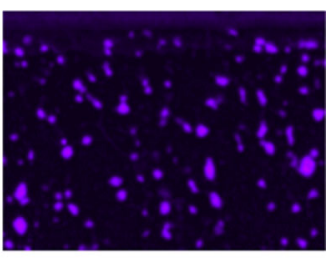

Ca

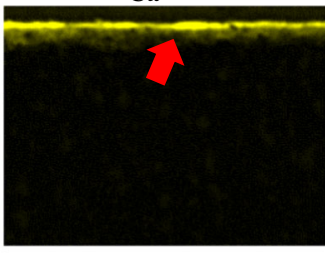

o

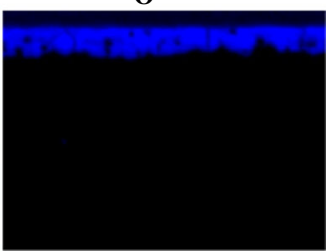

Fig. 9-continued.

presence possibly complicates the discussion for corrosion behaviors and their mechanisms. As for the present work, the Fe presence would not affect the following discussion and the conclusions based on them. Firstly, the present investigations were performed based on the same $\mathrm{Mg}-5 \mathrm{Nd}$ alloy. The role of $\mathrm{Fe}$ in all alloys was considered to be the same. Secondly, the harmful role of Fe can be reduced by the presence of rare earths. ${ }^{[62-64]}$ The rare-earth elements can interact with impurity elements $\mathrm{Fe}$ and $\mathrm{Ni}$ to form intermetallic compounds to lower the sensitivity of their cathodes. Present EDS analysis also confirmed the impurity particles contains $\mathrm{Nd}$ (Table III), indicating the interaction of $\mathrm{Fe}$ with $\mathrm{Nd}$ to form the intermetallic compounds. Thus, the following discussion focuses on the roles of $\mathrm{Mg}-\mathrm{Nd}$ intermetallics in influencing the corrosion resistance of $\mathrm{Mg}-5 \mathrm{Nd}$ alloy. In the present investigation, the influence of texture on corrosion resistance could be neglected. After hot extrusion, the intensity of texture is quite low with a maximum value of only 3.1 (Figure 10). Previous investigation showed that an addition of 0.08 at. pct $\mathrm{Nd}$ could effectively weaken the texture of the as-rolled $\mathrm{Mg}$ with maximum m. r. d of $6 .{ }^{[65]}$ Moreover, Hantzsche et al ${ }^{[65]}$ further indicated that the subsequent annealing at $400{ }^{\circ} \mathrm{C}$ could reduce the intensity of texture. $\mathrm{Mg}-5 \mathrm{Nd}$ (0.9 at. pct) has a much higher content of $\mathrm{Nd}$. In addition, all three alloys were investigated by solid solution treatment at a much higher temperature $530^{\circ} \mathrm{C}$. It can be conceivable that the texture in these three alloys should be much weaker with maximum m. r. d less than 3.1. Among them, the texture situation should be similar. Low temperature aging treatments at $200{ }^{\circ} \mathrm{C}$ or $245^{\circ} \mathrm{C}$ could not change the grain orientation.

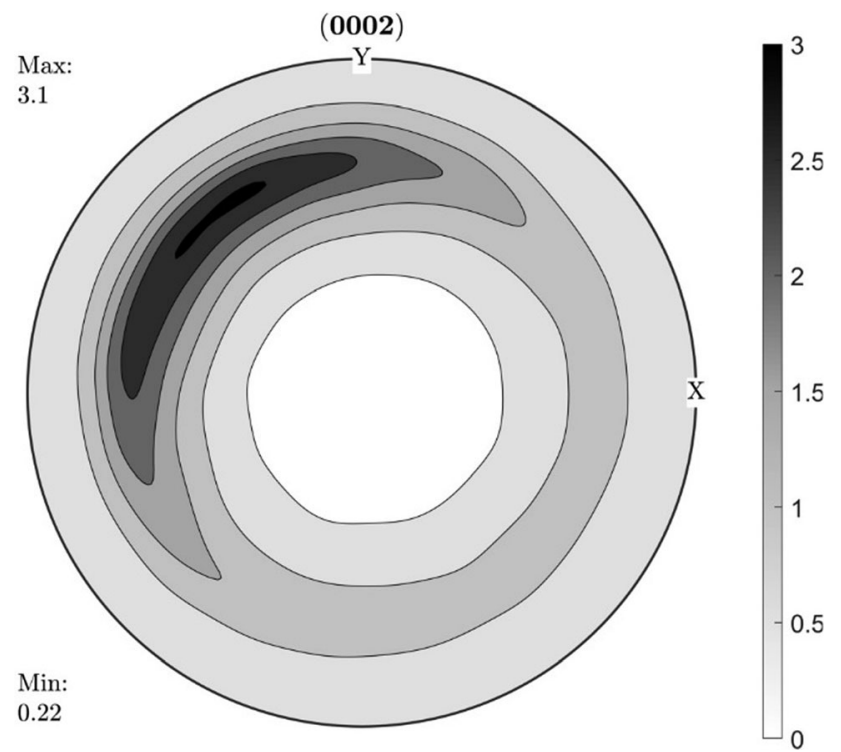

Fig. 10 - (0002)-pole figure of the as-extruded $\mathrm{Mg}-5 \mathrm{Nd}$ alloy.

\section{Corrosion proceeding influenced by intermetallic} microstructure

The results demonstrated that the corrosion started in localized regions (Figures 4, 6 and 8). The different microstructures achieved by heat treatments affect the corrosion initiation. In the T4 and A200 samples, the initial galvanic corrosion took place at the areas adjacent to isolated $\mathrm{Mg}_{41} \mathrm{Nd}_{5}$ intermetallic particles (Figures 4(b) and (d)). As mentioned, in these two samples very little local corrosion around Fe-containing particles was observed. When aged at a higher temper- 
ature of $245^{\circ} \mathrm{C}$, the corrosion initiations exhibited a difference from that observed in T4 and A245 samples. They initiated in the Nd-poor regions near the lamellar $\mathrm{Mg}_{41} \mathrm{Nd}_{5}$ particles (Figures 4(f) and 8). Schematic illustrations of corrosion initiation and propagation in T4, A200 and A245 samples are presented in Figure 11 when they were immersed under physiological conditions.

As known, $\mathrm{Mg}_{41} \mathrm{Nd}_{5}$ phase is thermodynamically stable. If compared to the $\mathrm{Mg}$ matrix, it is more cathodic in nature. In the T4 sample, there only exists one type of second phase $\mathrm{Mg}_{41} \mathrm{Nd}_{5}$. It is easy to understand why the corrosion initiated in the matrix around $\mathrm{Mg}_{41} \mathrm{Nd}_{5}$ particles. After aging, the metastable phase $\mathrm{Mg}_{12} \mathrm{Nd}$ precipitated out. Its precipitation seems not to affect the corrosion initiation at the early stage of immersion. Although in the A200 sample, significant amounts of nanometer $\mathrm{Mg}_{12} \mathrm{Nd}$ precipitates were homogeneously distributed inside grains and the corrosion still began in the matrix around these relatively large $\mathrm{Mg}_{41} \mathrm{Nd}_{5}$ particles. From thermodynamic theory, corrosion is driven by the potential difference between different phases. The potential difference between the equilibrium phase $\mathrm{Mg}_{41} \mathrm{Nd}_{5}$ and $\mathrm{Mg}$ is considered to be greater than that between the metastable phase $\mathrm{Mg}_{12} \mathrm{Nd}$ and $\mathrm{Mg}$.
$\mathrm{Mg}_{41} \mathrm{Nd}_{5}$ phase possesses a higher atomic percent of $\mathrm{Nd}$ than $\mathrm{Mg}_{12} \mathrm{Nd}$ that possibly elevates its potential. It was reported that the corrosion potential of $\mathrm{Mg}_{2} \mathrm{Al}_{3}$ phase, which has a higher atomic percentage of $\mathrm{Al}$, was greater than that of $\mathrm{Mg}_{17} \mathrm{Al}_{12}$ with a lower atomic percentage of A1. ${ }^{[34]}$ In the A245 sample, the lamellar $\mathrm{Mg}_{41} \mathrm{Nd}_{5}$ particles have a high potential as the globular $\mathrm{Mg}_{41} \mathrm{Nd}_{5}$ particles. Compared with the matrix in the T4 sample, in the A245 sample the Nd-poor matrix near these lamellar particles had a significantly lower potential. Previous investigations indicated that the solid solution of rare-earth elements in the $\mathrm{Mg}$ matrix could increase its corrosion potential. ${ }^{[28,66,67]}$ In addition, the high chemical activity and diffusivity of elements are also beneficial for the corrosion proceeding near grain boundaries. Consequently, the presence of $\mathrm{Nd}$-poor regions around these lamellar particles could enhance the galvanic corrosion. Similar results were reported by Yang et al. ${ }^{[66]}$ in which the Mg matrix with less Dy content is less corrosion resistant than that enriched with Dy.

The difference in corrosion initiation could result the different morphologies of interfaces between the corrosion layer and matrix (Figure 9). In both the samples of T4 and A200, owing to the fact that no preferential corrosion happened in the $\mathrm{Nd}$-poor regions and
T4
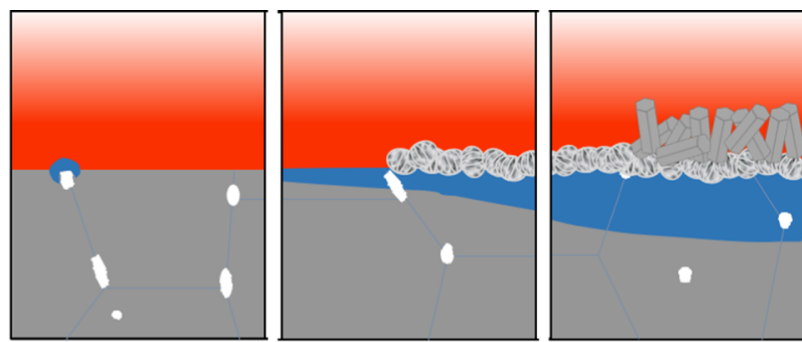

$\mathbf{A 2 0 0}$
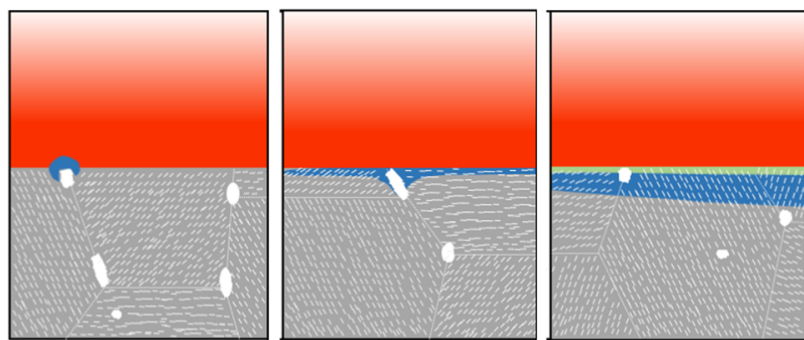

A245
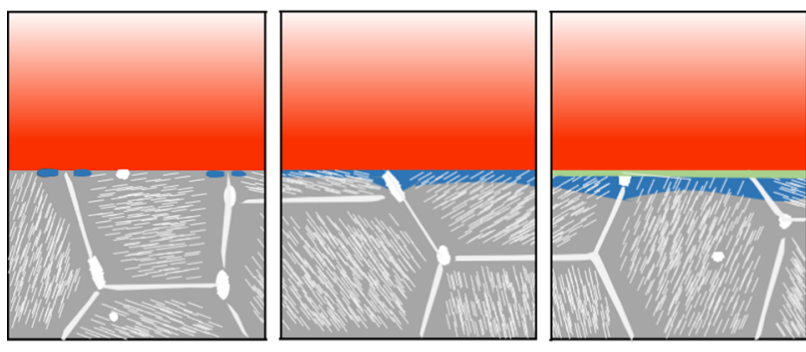

Short

Immersion time

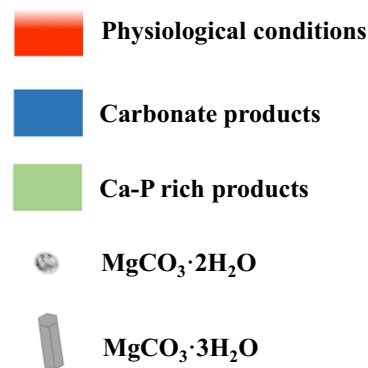

$\mathrm{gCO}_{3} \cdot 3 \mathrm{H}_{2} \mathrm{O}$

Fig. 11-Schematic illustrations of corrosion initiation and propagation in T4, A200 and A245 samples when they were immersed under physiological conditions. 
inexistence of continuous lamellae, the corrosion proceeded quite uniformly (Figure 4). As a result, in these two samples, the interfaces between the corrosion layer and matrix are smooth. In contrast, in the A245 sample, the corrosion preferentially started in the $\mathrm{Nd}$-poor regions, leading to these regions corroding more rapidly and the grain interiors corroding more slowly. On the other hand, the lamellar $\mathrm{Mg}_{41} \mathrm{Nd}_{5}$ particles were not degradable. After the dissolution of the matrix in close proximity to them, these remained continuous lamellar $\mathrm{Mg}_{41} \mathrm{Nd}_{5}$ particles stood out. All these resultant phenomena would cause the formation of a zigzag interface in the A245 sample (Figure 9(c)).

Once the corrosion started in the matrix near these globular or lamellar $\mathrm{Mg}_{41} \mathrm{Nd}_{5}$ particles, with the immersion proceeding it could propagate inside grains (Figure 11). The obtained results demonstrated although the nanometer precipitates $\mathrm{Mg}_{12} \mathrm{Nd}$ formed during aging they did not influence the corrosion initiation. They, however, indeed affected the corrosion propagation. Their dense and homogeneous distribution is helpful for resisting the propagation of corrosion into grain interiors and improving the corrosion resistance. Such a conclusion is supported by the measurements of degradation rate and the thickness observations of corrosion layers. As for the T4 sample without nanometer precipitates, it always had the highest corrosion rate during the entire immersion duration (Figure 5). Its corrosion layer is much thicker. While the corrosion layers of aged samples with nanometer $\mathrm{Mg}_{12} \mathrm{Nd}$ precipitates are much thinner (Figure 9). Moreover, the surface microstructural observations demonstrate that their grain interiors (Figure 8, labeled by yellow dots) remain without corrosion even after immersion for 7 days. The beneficial roles of profuse distribution of aging phases in alleviating the corrosion were also reported by previous investigators. ${ }^{[68]}$ In their work, it was found that these profuse micro-sized needle-like $\mathrm{Mg}_{12} \mathrm{ZnY}$-type phase and $\mathrm{Mg}_{5} \mathrm{Gd}$ could act as barriers between the matrix of $\mathrm{Mg}-\mathrm{Al}-\mathrm{Gd}$ alloys and $\mathrm{NaCl}$ solution. Their presence postponed the corrosion propagation. Despite both aiding to resist corrosion, the roles of nanoscale metastable phases inside grains in influencing the corrosion were reported to be different from that of continuous network phases at grain boundaries. ${ }^{[69]}$

During immersion of magnesium alloys in DMEM + Glutamax together with 10 pct FBS, their degradation led to the increase of $\mathrm{Mg}^{2+}$ concentration and $\mathrm{pH}$ value in solution, eventually resulting in the formation of degradation products including carbonates and $\mathrm{Ca}-\mathrm{P}$ salts, etc. ${ }^{[52,70]}$ In the corrosion layers of the investigated alloys, the components of the corrosion products are similar and include these carbonates and Ca-P salts. As the immersion was conducted under cell culture conditions, the presence of $\mathrm{CO}_{2}$ resulted in the formation of a $\mathrm{CO}_{2} / \mathrm{HCO}_{3}^{-}$buffering system. This buffering system further promoted the formations of carbonates on the surfaces of magnesium alloys. ${ }^{[4,71,72]}$ It was reported that their formations were quite complex. A slight change of corrosion parameters might lead to the formation of other members in the magnesium carbonate family. ${ }^{[71,73,74]}$

In the present investigation, in addition to the carbonate products a continuous and uniform $\mathrm{Ca}-\mathrm{P}$ rich product was formed in top of degradation products in A200 and A245 samples (Figures 9(b) and (c) and 11), but not in the T4 sample. It seems that in the aged samples it is easy to form at the beginning of corrosion. Previous works also identified the Ca-P products in corrosion layers, ${ }^{[7-78]}$ with a formation which is closely related with the presence of $\mathrm{Ca}^{2+}$ in simulated body fluids. Following the investigation of the present alloys, it is reasonable to conclude that the formation of the present outer Ca-P layer is connected with the content of $\mathrm{Nd}$ inside the matrix and microstructure. During immersion and degradation, the formation of corrosion products mainly depended on the reaction of degraded $\mathrm{Mg}$ matrix with corrosion media. In the present investigations, the corrosion medium used was the same. Thus, the difference should be caused by the alloys themselves. After aging, the content of $\mathrm{Nd}$ with solid solution in the matrix of A200 and A245 reduced. While in the T4 sample it was much higher. During degradation, the magnesium matrix with low $\mathrm{Nd}$ seemed to accelerate the formation of the outer Ca-P layer. In these two aged samples, the corrosion layers formed by the reaction of the $\mathrm{Mg}$ matrix with the corrosion medium were much more compact than that in the T4 solution treated sample. It is expected that it is much easier for the $\mathrm{Ca}^{2+}$ and $\mathrm{PO}_{4}^{3-}$ ions to diffuse inwards in the T4 sample. In contrast, their inwards diffusion becomes difficult in the corrosion layers of aged samples. Consequently, the $\mathrm{Ca}^{2+}$ and $\mathrm{PO}_{4}^{3-}$ ions preferentially deposited in the top of the corrosion layer in the aged samples. The corrosion layers can block the inwards diffusion of ions in corrosion medium was also reported by previous investigations. ${ }^{\text {[9] }}$ A detailed mechanism needs to be further clarified with future systematic investigations.

Finally, it is interesting to discuss how the precipitate evolution affects the corrosion of $\mathrm{Mg}-5 \mathrm{Nd}$. The corrosion results of A200 and A245 samples clearly indicated that the different precipitate microstructures influence the degradation behavior (Figures 4 and 5). It particularly plays an important role in affecting the corrosion propagation. At the early stage of corrosion, such as immersion with 7 days, the A200 sample exhibited better corrosion resistance than the A245 sample. However, it is reversed at the later stage of corrosion with immersion for 14 days. Normally, a more dispersive distribution of precipitates in the A200 sample should supply more obstacles to the corrosion propagation and thus it should exhibit a better corrosion resistance. However, this is not the case at the later stage of corrosion with an immersion duration of 14 days. Although in the A245 sample such a homogeneous distribution of coarse precipitates inside grains weakens and hinders the corrosion propagation, the existence of continuous lamellar precipitates along grain boundaries seems to supply additional obstacles to corrosion propagation. Microstructural observations demonstrated that after hot extrusion the grains of $\mathrm{Mg}-5 \mathrm{Nd}$ alloy are relatively small with an average size of $18.3 \pm 2.1 \mu \mathrm{m}$ (Figure 1 
and Table II). After the removal of the matrix at the later stage of corrosion, these exposed continuous lamellar precipitates with a relatively compact distribution (similar to distribution of grain boundaries) could effectively hinder the further propagation of corrosion, resulting in a better corrosion resistance for the A245 sample.

The present investigation shows that the type of second phase and its distribution influence the corrosion behavior of $\mathrm{Mg}-5 \mathrm{Nd}$ alloy. In a comparison of the three alloys investigated, the T4 alloy has the worst corrosion resistance. During immersion, when the corrosion started in the matrix around the globular $\mathrm{Mg}_{41} \mathrm{Nd}_{5}$ particles at grain boundaries, it then easily propagated into the grain interiors due to the shortage of obstacles supplied by the homogeneous distribution of nanometer $\mathrm{Mg}_{12} \mathrm{Nd}$ precipitates. The isolated presence of $\mathrm{Mg}_{41} \mathrm{Nd}_{5}$ particles could easily be dislodged during immersion (red arrows in Figure 8) and thus are also not effective obstacles to prevent the corrosion. On the other hand, on the surface of the T4 sample no outer dense Ca-P layer was formed. Instead, a loose layer of carbonate products was observed (Figure 6). Such the structure of corrosion layer could also accelerate its corrosion during immersion. It was reported that the calcium-phosphate layer could stabilize the surface $\mathrm{pH}$ value resulting in controlling $\mathrm{Mg}$ degradation. ${ }^{[78]}$ It plays a protective role to a certain extent in reducing the deterioration from the galvanic corrosion. ${ }^{[70]}$ Consequently, in the aged samples, owing to the formation of the outer Ca-P layer, the relatively compact inner corrosion layer and the dispersive distribution of nanometer precipitates inside grains, their corrosion resistance is better than the T4 sample.

\section{CONCLUSIONS}

The intermetallic phases in $\mathrm{Mg}-5 \mathrm{Nd}$ alloy with different heat treatments and their influence on the corrosion were investigated. The following conclusions were made:

1. In the T4 sample, only one intermetallic compound $\mathrm{Mg}_{41} \mathrm{Nd}_{5}$ is identified which is predominantly located at grain boundaries. Subsequent aging can lead to the homogeneous precipitation of metastable phase $\mathrm{Mg}_{12} \mathrm{Nd}$. With an increase in aging temperature from $200{ }^{\circ} \mathrm{C}$ to $245{ }^{\circ} \mathrm{C}$, the $\mathrm{Mg}_{12} \mathrm{Nd}$ precipitates grow. There is then a phase transformation from $\mathrm{Mg}_{12} \mathrm{Nd}$ to $\mathrm{Mg}_{41} \mathrm{Nd}_{5}$. Such a transformation starts at grain boundaries where the lamellar particles $\mathrm{Mg}_{41} \mathrm{Nd}_{5}$ are observed. Owing to the rapid consumption of $\mathrm{Nd}$ caused by their formation and growth, the $\mathrm{Nd}$-poor regions are found near these lamellar particles.

2. The intermetallic microstructure of $\mathrm{Mg}-5 \mathrm{Nd}$ alloy influences its corrosion behavior. The corrosion first begins in the matrix around the stable globular $\mathrm{Mg}_{41} \mathrm{Nd}_{5}$ particles at grain boundaries. In the sample aged at high temperature $245{ }^{\circ} \mathrm{C}$, the coexistence of lamellar $\mathrm{Mg}_{41} \mathrm{Nd}_{5}$ particles and their nearby $\mathrm{Nd}$-poor regions enhances the corrosion. The corrosion first starts in such regions.

3. These finely dispersed precipitates formed during aging have no influence on the corrosion initiation. However, they affect the subsequent corrosion propagation with the immersion proceeding. They supply barriers for corrosion propagation and hence are beneficial for improving the corrosion resistance. The continuously distributed lamellar $\mathrm{Mg}_{41} \mathrm{Nd}_{5}$ precipitates formed at grain boundaries during aging at $245{ }^{\circ} \mathrm{C}$ supply an additional effective obstacle to corrosion propagation. This is especially beneficial for hindering the corrosion propagation at the later stage of corrosion.

4. On the surfaces of all $\mathrm{Mg}-5 \mathrm{Nd}$ samples, corrosion products with carbonates and $\mathrm{Ca}-\mathrm{P}$ salts are formed after immersion. The corrosion layer of T4 sample is much looser than that of aged samples.

5. The T4 sample has the poorest corrosion resistance due to the lack of finely dispersed precipitates inside grains, continuous lamellar particles along grain boundaries and outer Ca-P layer, and to the formation of a loose corrosion product layer. In contrast, the aged samples exhibit a better corrosion resistance due to their presence and to the formation of a compact corrosion layer.

\section{ACKNOWLEDGMENTS}

Open Access funding provided by Projekt DEAL. The authors acknowledge Mr. G. Meister for preparing the alloys and Ms. Maria Nienaber for measuring the texture. Yaping Zhang also gratefully thanks the China Scholarship Council for the award of a fellowship and funding (No. 201604910708).

\section{OPEN ACCESS}

This article is licensed under a Creative Commons Attribution 4.0 International License, which permits use, sharing, adaptation, distribution and reproduction in any medium or format, as long as you give appropriate credit to the original author(s) and the source, provide a link to the Creative Commons licence, and indicate if changes were made. The images or other third party material in this article are included in the article's Creative Commons licence, unless indicated otherwise in a credit line to the material. If material is not included in the article's Creative Commons licence and your intended use is not permitted by statutory regulation or exceeds the permitted use, you will need to obtain permission directly from the copyright holder. To view a copy of this licence, visit http://creat ivecommons.org/licenses/by/4.0/. 


\section{REFERENCES}

1. Y. Lu, Y.L. Chiu, and I.P. Jones: Mater. Charact., 2016, vol. 112, pp. 113-21.

2. S. Zhang, X. Zhang, C. Zhao, J. Li, Y. Song, C. Xie, H. Tao, Y. Zhang, Y. He, Y. Jiang, and Y. Bian: Acta Biomater., 2010, vol. 6, pp. 626-40.

3. C. Liu, P. He, P. Wan, M. Li, K. Wang, L. Tan, Y. Zhang, and K. Yang: J. Biomed. Mater. Res., Part A, 2015, vol. 103, pp. 2405-15.

4. E.B. Öcal, Z. Esen, A.F. Dericioğlu, and K. Aydınol: Mater. Chem. Phys., 2019, vol. 214, p. 122350.

5. Z. Li, X. Gu, S. Lou, and Y. Zheng: Biomaterials, 2008, vol. 29, pp. $1329-44$.

6. J.W. Seong and W.J. Kim: Acta Biomater., 2015, vol. 11, pp. $531-42$.

7. L. Yang, Y. Huang, F. Feyerabend, R. Willumeit-Römer, K.U. Kainer, and N. Hort: J. Mech. Behav. Biomed. Mater., 2012 , vol. 13, pp. 36-44.

8. B. Mingo, R. Arrabal, M. Mohedano, C.L. Mendis, R. del Olmo, E. Matykina, N. Hort, M.C. Merino, and A. Pardo: Mater. Des., 2017, vol. 130, pp. 48-58.

9. S.D. Wang, D.K. Xu, B.J. Wang, L.Y. Sheng, Y.X. Qiao, E.H. Han, and C. Dong: Corros. Sci., 2018, vol. 142, pp. 185-200.

10. M. Němec, A. Jäger, K. Tesař, and V. Gärtnerová: Mater. Charact., 2017, vol. 134, pp. 69-75.

11. W.R. Zhou, Y.F. Zheng, M.A. Leeflang, and J. Zhou: Acta Biomater., 2013, vol. 9, pp. 8488-98.

12. M.C. Zhao, M. Liu, G. Song, and A. Atrens: Corros. Sci., 2008, vol. 50, pp. 1939-53.

13. M.B. Kannan: Mater. Lett., 2010, vol. 64, pp. 739-42.

14. O. Lunder, J. Lein, T.K. Aune, and K. Nisancioglu: Corrosion, 1989, vol. 45, pp. 741-48.

15. Y.W. Song, E.H. Han, D.Y. Shan, C.D. Yim, and B.S. You: Corros. Sci., 2012, vol. 60, pp. 238-45.

16. R.H. Buzolin, M. Mohedano, C.L. Mendis, B. Mingo, D. Tolnai, C. Blawert, K.U. Kainer, H. Pinto, and N. Hort: Mater. Sci. Eng. A, 2017, vol. 682, pp. 238-47.

17. C. Shuai, Y. Yang, S. Peng, C. Gao, P. Feng, J. Chen, Y. Liu, X. Lin, S. Yang, and F. Yuan: J. Mater. Sci., 2017, vol. 28, pp. $130-80$.

18. N. Hort, Y.D. Huang, and K.U. Kainer: Adv. Eng. Mater., 2006, vol. 8, pp. 235-40.

19. S. Gorsse, C.R. Hutchinson, B. Chevalier, and J.F. Nie: J. Alloys Compd., 2005, vol. 392, pp. 253-62.

20. F. Feyerabend, J. Fischer, J. Holtz, F. Witte, R. Willumeit-Römer, H. Drucker, C. Vogt, and N. Hort: Acta Biomater., 2010, vol. 6, pp. $1834-42$.

21. F. Bär, L. Berger, L. Jauer, G. Kurtuldu, R. Schäublin, J.H. Schleifenbaum, and J.F. Löffler: Acta Biomater., 2019, vol. 98, pp. $36-49$.

22. N. Anisimova, M. Kiselevskiy, N. Martynenko, B. Straumal, R. Willumeit-Römer, S. Dobatkin, and Y. Estrin: J. Biomed. Mater. Res. Part B, 2019, vol. 108, pp. 167-73.

23. B. Smola, L. Joska, V. Březina, I. Stulíková, and F. Hnilica: Mater. Sci. Eng. C, 2012, vol. 32, pp. 659-64.

24. R. Walter and M.B. Kannan: Mater. Lett., 2011, vol. 65, pp. $748-50$.

25. M.A. Easton, M.A. Gibson, D. Qiu, S.M. Zhu, J. Gröbner, R. Schmid-Fetzer, J.F. Nie, and M.X. Zhang: Acta Mater., 2012, vol. 60, pp. 4420-30.

26. L.L. Rokhlin: Magnesium Alloys Containing Rare Earth Metals: Structure and Properties, CRC Press, Boca Raton, 2003.

27. S. Delfino, A. Saccone, and R. Ferro: Metall. Trans. A, 1990, vol. 21, pp. 2109-14.

28. J. KubÁSek and D. VojtĚCh: T. Nonferr. Metal. Soc., 2013, vol. 23, pp. 1215-25.

29. B. Sun, J. Tan, H. Zhang, and Y. Sun: Scr. Mater., 2019, vol. 161, pp. 6-12.

30. Y.M. Zhu, H. Liu, Z. Xu, Y. Wang, and J.F. Nie: Acta Mater., 2015, vol. 83, pp. 239-47.

31. Z. Xu, M. Weyland, and J.F. Nie: Acta Mater., 2014, vol. 75, pp. $122-33$.

32. L.Y. Wei, G.L. Dunlop, and H. Westengen: J. Mater. Sci., 1996, vol. 31, pp. 387-97.
33. J.W. Chang, X.W. Guo, P.H. Fu, L.M. Peng, and W.J. Ding: T. Nonferr. Metal. Soc., 2007, vol. 17, pp. 1152-57.

34. A. Südholz, N. Kirkland, R. Buchheit, and N. Birbilis: Electrochem. Solid-State Lett., 2011, vol. 14, pp. C5-C7.

35. J.W. Chang, P.H. Fu, X.W. Guo, L.M. Peng, and W.J. Ding: Corros. Sci., 2007, vol. 49, pp. 2612-27.

36. M. Cihova, E. Martinelli, P. Schmutz, A. Myrissa, R. Schäublin, A.M. Weinberg, P.J. Uggowitzer, and J.F. Löffler: Acta Biomater., 2019, vol. 100, pp. 398-414.

37. M. Cihova, P. Schmutz, R. Schäublin, and J.F. Löffler: $A d v$. Mater., 2019, vol. 31, p. 1903080.

38. N.G. Grün, P. Holweg, S. Tangl, J. Eichler, L. Berger, J.J.J.P. van den Beucken, J.F. Löffler, T. Klestil, and A.M. Weinberg: Acta Biomater., 2018, vol. 78, pp. 378-86.

39. Y.L. Xu, L. Wang, M. Huang, F. Gensch, K.U. Kainer, and N. Hort: Adv. Eng. Mater., 2018, vol. 20, p. 1800271.

40. F.R. Elsayed, N. Hort, M.A. Salgado Ordorica and K.U. Kainer: in Materials Science Forum (2011), pp. 65-68.

41. R. Wilson, C. Bettles, B.C. Muddle and J. F. Nie: in Materials Science Forum, (Trans Tech Publications Ltd., Zurich-Uetikon, Switzerland, 2003), pp. 267-72.

42. V. Kree, J. Bohlen, D. Letzig, and K.U. Kainer: Prakt. Metallogr. Pr. M., 2004, vol. 41, pp. 233-46.

43. N. Hort, V. Floss, S. Gavras, G. Wiese and D. Tolnai: in The Mineral, Metals \& Materials Society 2019, ed. V.V. Joshi et al., (San Antonio, Texas, 2019).

44. in: Standard Test Methods for Determining Average Grain Size (ASTM International, 2013).

45. J. Fischer, M.H. Prosenc, M. Wolff, N. Hort, R. Willumeit-Römer, and F. Feyerabend: Acta Biomater., 2010, vol. 6, pp. 1813-23.

46. E. ISO: German version: DIN EN ISO, 2008, pp. 10912-93.

47. R. Hou, J. Victoria-Hernandez, P. Jiang, R. Willumeit-Römer, B. Luthringer-Feyerabend, S. Yi, D. Letzig, and F. Feyerabend: Acta Biomater., 2019, vol. 97, pp. 608-22.

48. E.P.S. Nidadavolu, F. Feyerabend, T. Ebel, R. Willumeit-Römer, and M. Dahms: Materials, 2016, vol. 9, p. 627.

49. J. Gonzalez, R.Q. Hou, E.P.S. Nidadavolu, R. Willumeit-Römer, and F. Feyerabend: Bioact. Mater., 2018, vol. 3, pp. 174-85.

50. N.A. Agha, Z. Liu, F. Feyerabend, R. Willumeit-Römer, B. Gasharova, S. Heidrich, and B. Mihailova: Mater. Sci. Eng. C, 2018, vol. 91, pp. 659-68.

51. Z. Zhen, T.F. Xi, and Y.F. Zheng: Trans. Nonferr. Met. Soc., 2013, vol. 23, pp. 2283-93.

52. R.Q. Hou, N. Scharnagl, F. Feyerabend, and R. Willumeit-Römer: Corros. Sci., 2018, vol. 132, pp. 35-45.

53. J. Zheng and J.S. Reed: J. Am. Ceram. Soc., 1989, vol. 72, pp. $810-17$.

54. P. Vostrý, B. Smola, I. Stulikova, F. Von Buch, and B. Mordike: Phys. Status Solidi., 1999, vol. 175, pp. 491-500.

55. P.J. Apps, H. Karimzadeh, J.F. King, and G.W. Lorimer: Scr. Mater., 2003, vol. 48, pp. 1023-28.

56. J.F. Nie: Metall. Mater. Trans. A, 2012, vol. 43A, pp. 3891-3939.

57. C. Zhai, Q. Luo, Q. Cai, R. Guan, and Q. Li: J. Alloys Compd., 2019, vol. 773, pp. 202-09.

58. Y. Wang, Y. Huang, X. Meng, L. Wan, and J. Feng: J. Alloys Compd., 2017, vol. 696, pp. 875-83.

59. I. Kaur, W. Gust, and Y. Mishin: Fundamentals of Grain and Interphase Boundary Diffusion, Wiley Chichester, New York, 1995.

60. A. Atrens, S. Johnston, Z.M. Shi, and M.S. Dargusch: Scr. Mater., 2018, vol. 154, pp. 92-100.

61. L. Yang, G. Liu, L. Ma, E. Zhang, X. Zhou, and G. Thompson: Corros. Sci., 2018, vol. 139, pp. 421-29.

62. W.E. Mercer and J.E. Hillis, Report No. 0148-7191, SAE Technical Paper1992.

63. N. Birbilis, M.A. Easton, A.D. Sudholz, S.M. Zhu, and M.A. Gibson: Corros. Sci., 2009, vol. 51, pp. 683-89.

64. S. Han, S. Mu, and J. Du: Corrosion, 2019, vol. 75, pp. 1100-09.

65. K. Hantzsche, J. Bohlen, J. Wendt, K.U. Kainer, S.B. Yi, and D. Letzig: Scr. Mater., 2010, vol. 63, pp. 725-30.

66. L. Yang, L. Ma, Y. Huang, F. Feyerabend, C. Blawert, D. Höche, R. Willumeit-Römer, E. Zhang, K.U. Kainer, and N. Hort: Mater. Sci. Eng. C, 2017, vol. 75, pp. 1351-58.

67. N. Angrisani, J.M. Seitz, A. Meyer-Lindenberg, and J. Reifenrath: New Magn. Alloys, 2012, vol. 35, pp. 81-98. 
68. F. Lu, A. Ma, J. Jiang, Y. Guo, D. Yang, D. Song, and J. Chen: Corros. Sci., 2015, vol. 94, pp. 171-78.

69. A. Atrens, M. Liu, N.I.Z. Abidin and G.L. Song: in Corrosion of Magnesium Alloys, ed. G. L. Song, Woodhead Publishing, 2011, pp. 117-65.

70. D. Mei, S.V. Lamaka, J. Gonzalez, F. Feyerabend, R. WillumeitRömer, and M.L. Zheludkevich: Corros. Sci., 2019, vol. 147, pp. 81-93.

71. M. Kieke, F. Feyerabend, J. Lemaitre, P. Behrens, and R. WillumeitRömer: BioNanoMaterials, 2016, vol. 17, pp. 131-43.

72. J. Hofstetter, E. Martinelli, A.M. Weinberg, M. Becker, B. Mingler, P.J. Uggowitzer, and J.F. Löffler: Corros. Sci., 2015, vol. 91, pp. 29-36.

73. W. Cheng and Z. Li: Ind. Eng. Chem. Res., 2010, vol. 49, pp. 1964-1974.

74. P.J. Davies and B. Bubela: Chem. Geol., 1973, vol. 12, pp. 289-300.

75. P.K. Bowen, J. Drelich, and J. Goldman: Acta Biomater., 2014, vol. 10 , pp. 1475-83.
76. Y. Xin, T. Hu, and P.K. Chu: Acta Biomater., 2011, vol. 7, pp. $1452-59$.

77. D. Tie, F. Feyerabend, N. Hort, R. Willumeit-Römer, and D. Hoeche: Adv. Eng. Mater., 2010, vol. 12, pp. B699-B704.

78. S.V. Lamaka, J. Gonzalez, D. Mei, F. Feyerabend, R. WillumeitRömer, and M.L. Zheludkevich: Adv. Mater. Interfaces, 2018, vol. 5, p. 1800169.

79. L. Yang, N. Hort, D. Laipple, D. Höche, Y. Huang, K.U. Kainer, R. Willumeit-Römer, and F. Feyerabend: Acta Biomater., 2013, vol. 9 , pp. $8475-87$.

Publisher's Note Springer Nature remains neutral with regard to jurisdictional claims in published maps and institutional affiliations. 